LBL- -29018

DE91 005404

\title{
A MICROSTRUCTURAL STUDY OF CREEP AND THERMAL FATIGUE DEFORMATION IN 60Sn-40Pb SOLDER JOINTS
}

\author{
Dana Tribula \\ Department of Materials Science and Mineral Engineering \\ University of California \\ and \\ Center for Advanced Materials \\ Materials and Chemical Sciences Division \\ Lawrence Berkeley Laboratory \\ 1 Cyclotron Road \\ Berkeley, CA 94720
}

June 2, 1990

\section{DISCLAIMER}

\begin{abstract}
This report was prepared as an account of work sponsored by an agency of the United States Government. Neither the United States Government nor any agency thereof, nor any of their employees, makes any warranty, express or implied, or assumes any legal liability or responsibility for the accuracy, completeness, or usefulness of any infcrmation, apparatus, product, or process disclosed, or represents that its use would not infringe privately owned rights. Reference herein to any specific commercial product, process, or service by trade name, trademark, manufacturer, or otherwise does not necessarily constitute or imply its endorsement, recommendation, or favoring by the United States Government or any agency thereof. The views and opinions of authors expressed herein do not necessarily state or reflect those of the United States Government or any agency thereof.
\end{abstract}

This work is supported by the Director, Office of Energy Research, Office of Basic Energy Science, Material Sciences Division of the U.S. Department of Energy under contract No. DE-AC76SF00098. 
A Microstructural Study of Creep and Thermal Fatigue Deformation in $60 \mathrm{Sn}-40 \mathrm{~Pb}$ Solder Joints

by

Dana Tribula

\begin{abstract}
Thermal fatigue failures of solder joints in electronic devices often arise from cyclic shear strains imposed by the mismatched thermai exy ansion coefficients of the materials that bind the joint as temperature changes are encountered. Increased solder joint reliability demands a fundamental understanding of the metallurgical mechanisms that control the fatigue to design accurate accelerated probative tests and new, more fatigue resistant solder alloys. The high temperatures and slow strain rates that pertain to thermal fatigue imply that creep is an important deformation mode in the thermal fatigue cycle. In this work, the creep behaviour of a solder joint is studied to determine the solder's microstructural response to this type of deformation and to relate this tos the more complex problem of thermal fatigue. It is shown that creep failures arise from the inherent inhomogeneity and instability of the solder microstructure and suggest tha: small compositional changes of the binary neareutectic $\mathrm{Pb}-\mathrm{Sn}$ alloy may defeat the observed failure mechanisms. This work presents creep and thermal fatigue data for several near-eutectic $\mathrm{Pb}-\mathrm{Sn}$ solder compositions and concludes that a $58 \mathrm{Sn}-40 \mathrm{~Pb}-2 \mathrm{In}$ arid a $58 \mathrm{Sn}-40 \mathrm{~Pb}-2 \mathrm{Cd}$ alloy show significantly enhanced fatigue resistance over that of the simple binary material.
\end{abstract}




\section{INTRODUCTION}

The $\mathrm{Pb}-\mathrm{Sn}$ eutectic alloy is widely used as a joining material in the electronics industry. In this application the solder acts as both an electrical and mechanical connection within and among the different packaging levels in an electronic device. Advances in packaging technologies driven by the desire for miniaturization and increased circuit speed result in severe operating conditions for the solder joint and thus solder joint reliability problems. Specifically, the mismatched thermal expansion characteristics of the materials joined by the solder and he cyclic temperature fluctuations normally encountered during service constitute a condition of thermal fatigue for the constrained solder contact. This is especially a problem in the surface mounting of leadless components where a shearing of the solder joint occurs with each temperature excursion, Figure 1. Repeated temperature cycling, such as that associated with Joule heating as the device is turned on and off and environmental temperature changes, fatigues the solder joint, ultimately causing its failure. Increased solder joint reliability requires the design of accelerated tests to accurately predict fatigue lives and the development of new more fatigue resistart solder alloys. Both the design of probative tests and the development of improved solders require that the metallurgical mechanisms of fatigue failure be well understood.

However, from the metallurgical perspective the construction of a mechanistic theory of fatigue is quite difficult. The fatigue is driven by temperature. Since the mechanical properties of the solder are temperature dependent, they change continuously during the strain cycle. Furthermore, in most cases of interest, the peak ternperature approaches the melting point of the solder with the consequence that high temperature creep is an important deformation mode. Also, the high temperatures reached during the fatigue cycle cause microstructural changes in the two-phase eutectic material which further alter its properties. Microstructural changes are particularly likely since the solder is initially in an as-solidified 
structure that is unstable under thermo-mechanical processing. As a first step in effectively addressing the complex thermal fatigue problem, a fundamental understanding of the microstructure/property relationship in $\mathrm{Pb}-\mathrm{Sn}$ solders and its association with more simple, fatigue related deformation modes is desirable.

Past research on the thermal fatigue of solder joints has concentrated on the development of analytical models to predict fatigue lives based on accelerated fatigue test results. However, such models are valid only if they accurately reproduce the metallurgical mechanisms of failure in an accelerated time scale. Since much of this previous work has been done without accompanying microstructural analyses, the issue of joint failure mechanism has not yet been directly addressed.

The emphasis in this work is to examine the creep response of a solder joint and to relate this to the more complex thermal fatigue deformation. The high homologous temperatures and slow strain rates operative during thermal fatigue imply that creep deformation is a very relevant deformation mode, and, as will be shown here, creep in shear reproduces the failure mechanisms of thermally fatigued solder joints, thus further justifying a detailed creep study. We begin with a review of the microstructure/property/processing relationship in $\mathrm{Pb}-\mathrm{Sn}$ alloys and use this understanding to develop a mechanistic interpretation of the creep results and, as will be discussed, to identify possible paths towards the development of new solder materials. Finally, thermal fatigue experiments are used to test the proposed mechanisms and evaluate new solders. 


\section{BACKGROUND}

\section{Eutectic Microstructures: Solidification Effects}

A central principle of Materials Science states that a material's properties originate not only from its atomic composition but also from the atomic arrangements within that material - the material's microstructure. However, for a material of a given chemical composition, the material's microstructure is not constant, but can vary greatly with its processing history. It follows that if one is to understand and control the mechanical behaviour of solder joints, one must begin not only with an understanding of the solder microstructure but also an understanding of its origin in terms of various processing parameters. In the case of solder alloys, the application dictates use in the as-cast state, and hence, the cooling rate of the alloy is the only variable processing parameter. The local cooling rates of a solder contact depend on many factors, including the soldering process, the specific solder joint thickness and geometry, the composition and configuration of the carrier board and the neighboring components. To understand the effect of cooling rate on solder joint microstructure and thus mechanical properties, it is instructive to first consider more simple solidification scenarios and the resultant solder microstructures.

\section{Lamellar Eutectics}

In the case of preferentially oriented plane-front steady-state growth, the eutectic $\mathrm{Pb}-\mathrm{Sn}$ material grows as alternating lamellae of the two constituent phases parallel to the direction of growth. Eutectic solidification is a cooperative growth process since the solute rejected ahead of one phase region becomes immediately incorporated as the solvent phase in the adjacent region, and the plates thus grow at the same rate. Many lamellae constitute a lamellar grain and will continue to grow in such a coupled manner until contact with a mould wall or a similarly growing grain. A distinct boundary delineates two adjacent eutectic grains; an example appears in Figure 2. The lamellar spacing within the eutectic 
grain is determined by the cooling rate. A faster cooling rate results in fine lamellae, and, in the case of a miultigraineu structure, the eutectic grains will be smaller and the lameliar spacing within each grain will be finer [e.g. 1-3]. The microstructural features that make up such a structure are the eutectic grain size, and the finer phase structure contained within.

It is important to note, that within such a morphology, many individual phase regions - e.g. the lamellae, constitute a single eutectic grain. Within these eutectic grains all phase regions of the same kind exhibit a single and constant crystallography, and there is a unique and preferred crystallographic interface plane between the two constituent phases [3-8]. The lamellar grain just described is, in fact, two single crystallites of the two constituent phases [7,9-11]. The crystallographic relationships within and between the two phases are those that minimize growth and interfacial energies for a given set of solidification conditions. The stability of the liquid/solid interface determines the inter- and intra-phase crystallographic and morphological perfection [4-7].

\section{Degenerate Eutectics}

A breakdown of the lamellar structure results from instabilities of the advancing liquid/solid interface. The resultant morphology may be wavy, rod-like or globular (termed degenerate lamellar), and lacks the long range perfection of the regular lamellar structures.[6] Interface instabilities may arise from growth along unfavorably uriented growth directions, local supercooling effects and rapid cooling rates.[5-7] Solidification under such conditions results in discontinuities and faults of the individual phase regions and phase interfaces that disrupt the continued growth of the aligned lamellar structure. Instead, only a short range phase alignment is maintained and a colony sub-structure develops within the individual eutectic grain. The colony is a subset of the eutectic grain and is characterized as a shortrange phase alignment over a region of the eutectic grain separated from other eutectic colonies by a small crystallographic mismatch. Figure 3 schematically illustrates several 
features of a eutectic microstructure including the colony structure within the eutectic grain [12]. These degenerate structures lack the structural perfection of the lamellar eutectics, especially at the colony boundaries. However, they do maintain a special and unique crystallographic alignment with the growth direction and, as much as possible, between the two phases.

A dramaticaliy different microstructure is obtained by quenching of the $\mathrm{Pb}-\mathrm{Sn}$ eutectic material from the melt [13]. In this case, solidification occurs so quickly that the eutectic colony formation is suppressed, and instead the microstructure appears as a dispersion of the $\mathrm{Pb}$-rich phase in a Sn-rich matrix. The quenched microstructure, unlike the slower cooled eutectic colony stucture, is uniform in phase size and shape distribution throughout the entirety of the specimen. And, unlike the eutectic grain structure described above, there is no apparent crystallographic relationship between the two phases; each individual phase region appears to be an individual phase grain. Figure 4 shows a bulk $\mathrm{Pb}-\mathrm{Sn}$ eutectic specimen w'ater quenched from $230^{\circ} \mathrm{C}$. In contrast to a more moderately cooled specimen, the quenched microstructure is much finer and lacks the morphological heterogeneity that characterizes the colony structure.

The description of a eutectic microstructure is not straightforward. Unlike a single phase material, a grain size is not readily apparent. Miuch of the published work on solder microstructures uses the phase diameter, i.e. the average diameter of a phase region in a two dimensional section, as the grain size. The phase diameter, may in fact not be a true grain at all. By definition, a grain refers to an element of a material within which a single crystallography exists. In a eutectic structure, many individual phase regions, as seen in a two dimensional section, may, in fact, be a part of a single eutectic grain (e.g. the two lamellar grains in Figure 2). The terminologies that apply to eutectic microstructures, as established by Weart and Mack [14], include the eutectic grain, the eutectic colony and the individual phase regions. The eutectic grain refers to that portion of the structure which 
nucleated at a single site and which shares a specific and unique crystallography. The eutectic colony may be a subset of a eutectic grain and refers to a region within the microstructure where the phase particles have a characteristic arrangement. 


\section{Solder Joint Microstructures}

In a casting, such as a solder joint, solidification initiates from many different nucleation events. A favorably oriented seed may not be present and the cooling rate is such that there is insufficient time to select preferred growth directions. The final microstructure will thus contain both lamellar and degenerate eutectic features within a eutectic colony/grain arrangemerit. The distribution and size of these varies with global and local cooling rates, with larger lamellar eutectic colonies/grains dominating at slower cooling rates. Such a microstructure is characterized by a local homogeneity - within a eutectic colony/grain and a global inhomogeneity as the phase features differ from eutectic grain to eutectic grain and, especially, at the eutectic colony/grain boundary. Faster cooling rates yield progressively less distinct eutectic colony/grain structures and an increasingly more degenerate and globally uniform structure.

In the solder microstructures that are described in this work no distinction is made between a eutectic grain and a eutectic colony. The term eutectic colony here refers to a region of the microstructure that exhibits a specific phase particle size and shape arrangement. For convenience, the term colony is being used to distinguish it from the grain size referred to in the superplastic and highly degenerate structures where an individual phase region constitutes in fact an individual crystallographic grain. It should be noted that polarized light microscopy of the colony/grain structures studied here reveals constant contrast within a colony feature and contrast changes between these eutectic structural features, and stching of the colony structure reveals grain boundary contrast only in the degenerate material at the colony boundaries, thus indicating that the colonies are indeed single, continuous crystallographic units.

Intermetallics. Since a $\mathrm{Pb}-\mathrm{Sn}$ solder joint most frequently occurs on a $\mathrm{Cu}$ substrate, another microstructural component of the $\mathrm{Pb}-\mathrm{Sn}$ solder joint is the intermetallic layer at the 
$\mathrm{Cu} /$ solder interface. The intermetallics form when the molten solder comes into contact with the clean $\mathrm{Cu}$ surface. In near eutectic $\mathrm{Pb}-\mathrm{Sn}$ solders the intermetallic phase is a double layer. $\mathrm{Cu}_{3} \mathrm{Sn}$ grows as densely packed globular particles directly on the $\mathrm{Cu}$ surface and the $\mathrm{Cu}_{6} \mathrm{Sn}_{5}$ grow as hexagonal rods that protrude out into the bulk of the joint. During solidification, turbulence in the melt causes these spikes to break off and they appear as intermetallic particles in the bulk of the joint material [15]. Figure 5 shows detail of the interfacial and bulk intermetallic phase. It has been shown that the intermetallics have little influence on the solder mechanical properties reviewed in this work.[6,16-18]

\section{Effects of Composition}

A relaxation of the regularity and perfection of the eutectic lamellar structure is possible with a small addition of a third element [19] During solidification, the third element in the eutectic $\mathrm{Pb}-\mathrm{Sn}$ alloy, acting analogously to an impurity in a single component system, will be rejected from the solidifying phases into the remaining liquid. (This analogy is valid when the partition coefficient is $<1$, as is expected here based on an analysis of the binary diagrams of common impurities and the constituent phases) [1-3]. The resultant compositional changes can result in an area of constitutional supercooling directly ahead of the advancing solid/liquid interface and allow for the perturbation and break down of the solidification front into a colony/cellular structure. The coarser and irregular features at the colony boundaries result from the slower growth rates encountered at the curved colony/cell interfaces $[3,11,12,14,20,22]$.

\section{Recrystallized Pb-Sn Microstructure}

A very different $\mathrm{Pb}-\mathrm{Sn}$ microstructure is achieved after a mechanical working of the assolidified $\mathrm{Pb}-\mathrm{Sn}$ material. The plastic deformation introduced with, for example, rolling, swaging or extrusion of the as-cast bulk solder introduces a very high dislocation density into the $\mathrm{Pb}-\mathrm{Sn}$ microstructure which in turn initiates a recrystallization of the deformed 
material. The recrystallization process involves the nucleation of new strain-free grains in the deformed material which grow until the latter is consumed. Thermal energy above some threshold is necessary to initiate this process; however, since solder is already at a high homologous temperature at $25^{\circ} \mathrm{C}$, recrystallization may occur dynamically as the material is being deformed. The recrystallized microstructure consists of equiaxed, randomly oriented grains of the two constituent phases uniformly distributed throughout the material. As shown in Figure 6, this type of $\mathrm{Pb}-\mathrm{Sn}$ microstructure bears little resemblance to the eutectic colony structure that is charasteristic of the normally cooled, assolidified material. The ease of recrystallization and the dramatic difference in appearance of the recrystallized material are well documented for this alloy [21-24].

\section{Coarsening Behaviour}

The coarsening behaviour of as-cast eutectics varies significantly with the various possible morphologies. The perfect, lamellar structures exhibit exceptionally high morphological stability at elevated temperatures $[4,25-29]$. This contrasts greatly with the rapid spheroidization and coarsening of the more faulted degenerate and dispersed structures and the irregularly shaped material comprising the colony boundaries. Coarsening always initiates in these less regular regions and very slowly consumes the more perfect material. The difference is atributed to the the higher interfacial energies of the less favorably aligned structures and the enhanced diffusion afforded by the greater fault and grain boundary areas.

\section{Eutectic Microstructure:-Mechanical Properties}

Just as the processing history determines a material's microstructure, the microstructure, in turn, determines the mechanical properties. Since the $\mathrm{Pb}-\mathrm{Sn}$ eutectic structure exhibits dramatically different morphologies with different processing histories, it is not surprising that these different microstructures exhibit significantly different mechanical properties. 


\section{Eutectic Structures}

Of the microstrictures possible within this alloy system, the regular lamellar microstructures that characterize the as-cast $\mathrm{Pb}$-Sn eutectic material possess the highest yield strengths and creep resistances and the lowest elongations and strain rate sensitivities $[21,22,30-34]$. The exceptional strengths are attributed to the large-scale, regular arrangement of the lamellar structure and the associated difficulty of dislocation motion through the aligned two phase structure [9]. Deformation of the multigrained material is most easily accommodated at the eutectic colony/grain boundaries where these strengthening mechanisms are less effective. For a multi-colony structure, such as that observed in the experimental (this work) and real device [35] solder joints in Figures 7 and 8, a highly inhomogeneous deformation character is thus expected. Deformation is more easily accommodated in the degenerate, and thus softer, intercolony areas than in the stronger, regularly aligned phase arrangement inside the colony. This is readily apparent on observing the pattem of surface relief that develops on a flat, polished eutectic colony structure as it is deformed. Figure 9 shows such a pattern. Relatively little deformation occurs in the colony interior; rather, the surface relief indicates that the strain is accommodated by the degenerate material at the colony boundaries. Furthermore, microhardness traces across such a eutectic structure, as shown in Figure 10, illustrate that the irregular phase arrangement at the colony boundary is softer than the regular phase arrangement within the eutectic colonies. Processing changes that reduce the colony size and thus increase the amount of soft boundary material predictably impact the observed mechanical properties. Castings of bulk specimens show a dramatic decline in the yield strength $[31,36]$ and creep resistance, and increase in strain rate sensitivity and elongation [32] with faster cooling rates. Faster cooling rates increase the amount of degenerate irregular material through reduced colony size and reduced structural perfection, and thus lead to an overall softening of the material. 
The shear strengths of the ternary alloys evaluated in this work appear to follow a similar trend. The alloys that exhibit the greatest volume of lamellar aligned eutectic material also exhibit the highest shear strengths. The Cd-and In-alloyed solders, those microstructures possessing larger fractions of irregular degenerate phase particles exhibit slightly lower yield strengths. Since the third elements studied here all go into solution in the $\mathrm{Pb}$ and $\mathrm{Sn}$ phases, an increase in shear strength is predicted as a result of solid solution strengthening effects. However, the third element also disturbs the solidification behaviour and thus the final microstructure. In fact, for the alloys studied here, the microstructural effect is to increase the amount of degenerate eutectic material. Taken a'sne, this microstructural modification predicts a decline in strength. The $\mathrm{Sb}$ and $\mathrm{Bi}$ addition results in a small microstructural change and a modest increase in shear strength [12]. The strength increase can be justified as a solid solution strengthening that is sufficient to overcome the softening expected with the microstructural change. The $\mathrm{Cd}$ and In additions more drastically "soften" the microstructure, and also slightly decrease the shear strength [12]. Given this information alone, it is not possible to extract a possible solid solution strengthening effect from the miciostructural effect. Table 1 lists the shear strength data for the various alloys. All data refer to the specimen configuration in Figure 11.

An even greater difference in mechanical behaviour is exhibited by recrystallized $\mathrm{Pb}-\mathrm{Sn}$ material. Within this homogeneous, fine grained microstructure the strengthening mechanisms associated with the composite nature of the lamellar eutectic are lost and the deformation character is greatly altered. The fine equiaxed grain size and associated large grain boundary area contribute to the exceptional softness and ductility of the recrystallized microstructure [2i,37-40]. In fact, under the appropriate deformation conditions, this type of microstructure is superplastic exhibiting elongations in excess of hundreds of percent. 


\section{EXPERIMENTAL}

This work includes a measurement of creep properties, preliminary thermal fatigue experiments, and a correlation of these with the solder joint microstructure.

The two joint configurations used in this study are schematically shown in Figures 11 and 12. Figure 11 is the specimen used in the creep and shear strength tests. The sample is a three layer $\mathrm{Cu}$ sandwich joined with solder. The dual slot configuration has the consequence that on tensile loading the enclosed central solder joint regions (shaded areas in the Figure) are deformed in simple shear. Sample preparation consists of a polish, etch and flux of the $\mathrm{Cu}$ plates, assembly with appropriate spacers to yield the desired joint width, and immersion into a molten solder bath. The entire solder ingot containing the $\mathrm{Cu}$ plate assembly is then cooled. Excess solder is removed and the $\mathrm{Cu} / \mathrm{solder}$ sandwich is sliced to yield the individual test specimens. A final machining step to each slice yields the specimen shown in the Figure. This process is advantageous in that each $\mathrm{Cu} / \mathrm{solder}$ assembly yields 10-12 individual test specimens that share an identical manufacturing history.

The sample used for creep experiments is that diagrammed in Figure 11. Creep experiments were conducted by applying a constant tensile load to the specimen, which imposes a constant nominal shear stress on the central joints in the sample that transmit the load. The shear strain is measured as a function of time at a given shear stress and temperature. An extensometer mounted on the specimen such that it straddles the central solder joints measures joirt extension. The shear strain, $\gamma$, is defined as the ratio of joint extension to initial joint width, $\Delta \mathrm{l} / \Delta \mathrm{w}$ (see Figure 11). The creep tests were used to measure the steady-state creep rate, $\dot{\gamma}$, of the solder as a function of shear stress, $\tau$, for comparison with conventional steady state creep data. 
Figure 12 is the specimen used in the thermal fatigue testing. The sample preparation is identical to the previous specimen, except that the central $\mathrm{Cu}$ plate has been replaced with a $\mathrm{Ni}$ and $\mathrm{Cu}$ plated Al plate. After slicing, several holes are drilled tisrough the solder to isolate individual sections of the solder joint. It is the thermal expansion mismatch between the $\mathrm{Cu}$ and $\mathrm{Al}$ that will drive the fatigue during temperature cycling. Since the shear strain in the solder joint increases from the center of the assembly to a maximum at the specimen edges, the holes also serve to isolate solder joints at a particular shear strain.

The thermal fatigue specimens were cycled between a high temperature, $125^{\circ} \mathrm{C}$, bath and a low temperature, $-55^{\circ} \mathrm{C}$, bath. The time spent in each bath was 90 seconds with a 90 second transfer time. Total cycle time was $\cong$ six minutes. A temperature/time profile for a specimen as it is being cycled is shown in Figure 13.

The shear strain was calculated according to

$$
\gamma=\Delta \alpha \Delta \mathrm{T} 1 / \mathrm{w}
$$

where $\gamma$ is the shear strain, $\Delta \alpha$ is the difference in thermal expansions, $\Delta \mathrm{T}$ is the temperature change, $l$ is the distance from the center of the joint and $w$ is the joint width (see Figure 12). The values used in this equation are: $\alpha_{\mathrm{C} u}=21 \times 10^{-6} /{ }^{\circ} \mathrm{C}$, $\alpha_{\mathrm{Al}}=17 \times 10^{-6} /{ }^{\circ} \mathrm{C}, \mathrm{w} \sim 2.5 \times 10^{-4} \mathrm{~m}(0.010$ inches $), 1 \sim 0.04 \mathrm{~m}(1.5$ inches $)$ and $\Delta \mathrm{T}=180^{\circ} \mathrm{C}$. The joints examined in thi: work correspond to nominal shear strains up to $23 \%$ for a $-55^{\circ} \mathrm{C}$ to $125^{\circ} \mathrm{C}$ temperature excursion.

Additionally, the microstructural response to these deformation modes of the solder joints was evaluated. All joints were examined prior to deformation and immediately after. The surface relief that is associated with deformation was clearly visible under an optical microscope after 
deformation. A final polishing of the deformed microstructure to remove the surface relie $\hat{i}$ allows for a compärison of initial, as-deformed and final microstructures.

The polishing procedure was as follows: 600 grit Carbimet paper, $6 \mu \mathrm{m}$ diamond paste (kerosene), 1 and $0.5 \mu \mathrm{m}$ alumina powder (water), and a final polish using Buehler Masternet (colloidal silica suspension in a highly basic solution). This polishing procedure resulted in sufficient contrast between the two phases that an etching step was not necessary. However, to reveal the grain structure within a phase region, the following etchant was used: $5 \mathrm{ml} \mathrm{HCl}, 25 \mathrm{ml} \mathrm{H} 2 \mathrm{O}$, ard $5 \mathrm{~g} \mathrm{NH}_{4} \mathrm{NO}_{3}$. Both optical and SEM microscopy were used. In optical microcopy, the $\mathrm{Pb}$-rich phase appears dark and the $\mathrm{Sn}$ rich phase is light. This contrast is reversed in SEM microscopy.

Ternary alloys were manufactured from commercially purchased eutectic solder and appropriate additions of the third element and additional $\mathrm{Pb}$ to attain a $58 \mathrm{Sn}-40 \mathrm{~Pb}-2 \mathrm{X}$ wt\% composition, where $\mathrm{X}=\mathrm{Bi}, \mathrm{Sb}, \mathrm{Cd}$ and $\mathrm{In}$. When making the solder joints, the appropriate alloy was heated to $250^{\circ} \mathrm{C}$ and the preheated $\mathrm{Cu}$ block and spacer assembly was submerged into it. The quartz and graphite crucible were then immersed in ice water to cool the ingot. All specimens were prepared in such a manner. 


\section{RESULTS}

\section{Mictostructures}

Binary Alloys

The initial $60 \mathrm{Sn}-40 \mathrm{~Pb}$ microstructure appears in Figure 7. The microstructure is a mixture of the $\mathrm{Pb}$-rich and $\mathrm{Sn}$-rich phases. ( $\mathrm{Pb}$ rich phase appears dark and the $\mathrm{Sn}$ rich phase appears light in optical microscopy). The $\mathrm{Pb}$-rich phase appears both as primary $\mathrm{Pb}$-rich dendrites and as a constivuent of the eutectic microstructure. The eutectic microstructure consists of alternating $\mathrm{Pb}$-rich and $\mathrm{Sn}$-rich phase regions distributed within eutectic colonies. A specific phase particle size and shape arrangement distinguishes a single eutectic colony. The phase particle morphology within a colony may be lamellar or globular. The boundary between neighboring colonies is often very distinct and delimited by a narrow region of enlarged equiaxed phase particles. Polarized light microscopy of the colony/grain structure reveals constant contrast within a colony feature and contrast changes between these eutectic structural features. Etching of the colony structure reveals grain boundary contrast only in the colony boundary areas. These observations indicate that the colonies are single continuous crystallographic units. The colony size is almost on the order of joint thickness.

A comparison between the $60 \mathrm{Sn}-40 \mathrm{~Pb}$ solder microstructure of the experimental joint used in this work, Figure 7, with the microstructure of a real device solder joint, Figure 8, reveals similar microstructures.

Temary Alloys

The as-solidified microstructures of the ternary alloys are shown in Figures 14. All specimens were manufactured using identical processing techniques; hence microstructural changes are a result of compositional changes only. The addition of Sb has little influence 
on the microstructure, except for a slight diffusion of eutectic colony boundary area. Similar to the binary alloys, a fine microstructure exhibiting distinct individual eutectic colonies exists. Phase particle sizes and shapes are similar to those observed for the 60Sn$40 \mathrm{~Pb}$ alloy. The $\mathrm{Bi}$ addition changes the character of both the colony macrostructure and the eutectic microstructure within. The colony structure appears equiaxed and smaller relative to the binary and $\mathrm{Sb}$ ailoys. The eutectic structure within the colonies is no longer uniform, but varies from the colony center to the colony periphery. The central zone consists of very fine, regularly arranged parallel phase particles. The peripheral zone is composed of enlarged phase particles of smaller aspect ratio. A similar microstructure is observed for the In-alloyed solder: small colonies consisting of both fine and coarse phase particles. Compared to the Bi-alloyed solder, the colonies are smaller and the total amount of degenerate material is larger. The Cd-alloyed solder exhibits the least distinct colony structure. Small regions of fine parallel phase particles are observed, however they comprise a much smaller fraction of the sample than that taken up by the degenerate intercolony microstructure. In contrast to the alloys previously discussed, the intra-colony microstructure is equiaxed with no apparent arrangement between the two phases.

To summarize, the addition of third elements appears to affect the colony macrostructure as well as the eutectic microstructure contained therein. All ternary alloys exhibited a refinement of the eutectic colony size relative to the binary alloy. The appearance of diffuse colony boundaries and a degeneracy of the structure within the colony with additions is also very distinct. These changes are the greatest for the In- and Cd-alloyed solders. Xray analysis on the SEM (KEVEX) confirmed the presence of $\sim 1.5-2.0 \mathrm{wt} \%$ of the third element in all the ternary solders. X-ray mapping failed to reveal a preferred segregation of the third element in any of the microstructures. 


\section{Creep Data}

Figure 15 shows a typical creep curve. All three creep regimes are exhibited. Primary creep is active for the first $\sim 2 \%$ of the creep strain, and is present in all specimens tested. The steady-state regime consumes the next $\sim 10 \%$ strain. All samples exhibited an obvious second stage creep regime, although its extent varied among the different specimens. For the simple binary compositions, steady-state creep accounted for about $6-8 \%$ of total strain and about $10-14 \%$ of total strain in the In and Cd compositions. These data are for strain rates in the $10^{-4} \mathrm{sec}^{-1}$ to $10^{-6} \mathrm{sec}^{-1}$ range.

The strain rate in the steady-state creep range, at constant temperature, is plotted vs. the corresponding stress in Figure 16 for the eutectic $\mathrm{Pb}-\mathrm{Sn}$ alloy. The linearity of the data on the $\log / \log$ plot indicates a power law dependence between strain rate and stress. In this particular case (61.9Pb-38.1Sn), the slope (the stress exponent, $n$, in (2)), has a value of 6.3 .

A series of constant stress steady-state strain rates as a function of inverse temperature, is plotted in Figure 17 for the $\mathrm{Cd}$ alloy. Linearity on the semilogarithmic plot is characteristic of an Arrhenius type temperature dependence. The data for the Cd alloy shown here indicate an activation energy for creep of $66.9 \mathrm{~kJ} / \mathrm{mole}$ ( $16 \mathrm{kcal} / \mathrm{mole})$.

The complete set of stress exponents and activation energies for the alloys studied appear in Table 1. Also tabulated is a value for $\log \mathrm{A}^{\prime}$ to allow for comparison with other published data. The nomenclature refers to the following equation:

$$
\frac{d \gamma}{d t}=A \tau^{n} e^{-E_{a} / k T} ; \quad \frac{d \gamma}{d t}=A^{\prime} \tau^{n},
$$


where $\frac{\mathrm{d} \gamma}{\mathrm{dt}}$ is the steady-state shear strain rate, $\tau$ is the shear stress, $\mathrm{E}_{\mathrm{a}}$ is the activation energy associated with a particular creep deformation mechanism, $\mathrm{n}$ is the stress exponent (a semi-empirical constant $\mathrm{r}$; resenting the stress dependence of a given deformation mechanism), the constant $\mathrm{A}$ includes material specific information including a parameter describing the microstructure, $A^{\prime}$ is a constant that represents the product $A e^{-E_{a} / k T}$.

\section{Microstructural Evolution During Creep Deformation}

\section{Binary Alloys}

Figure 18 (top) shows the deformation pattern that forms when the solder joint diagrammed in Figure 11 is deformed slowly in shear. Figure 18 (bottom) shows the same joint after a light polish to remcve the surface relief. The deformation pattern is easily observed by polishing the surface of the solder joint prior to testing and observing the surface relief that appears as the joint deforms. The most common pattern is that shown in Figure 18 (top) consisting of a nearly straight band of deformation that runs slightly displaced and parallel to the $\mathrm{Cu} /$ solder interface along the direction of maximum shear and more irregular deformation features that lie approximately perpendicular to this direction. A comparison of the deformation pattern and the corresponding polished solder joint surface reveals the direct correspondence between the deformation and the location of microstructurally coarsened material. The definition of the coarsened band and the microstructure within are seen in greater detail in Figure 19. The material within the coarsened band consists of equiaxed, coarsened grains of the $\mathrm{Sn}$ - and $\mathrm{Pb}$-rich phases with no trace of the initial assolidified colony structure visible. Closer inspection shows that the parallel band in Figure 18 (bottom) traverses eutectic colonies, while the perpendicular coarsening occurs at colony boundaries. In all cases, the parallel deformation originates at a lateral free surface of the joint, a point that corresponds to the principal stress concentration in this sample geometry, 
see Figure 20 [41]. Joint cracking and failure always initiate exclusively within this coarsened band.

A slightly different scenario is observed for creep deformation at slower strain rates. Figure 21 shows the surface relief and corresponding microstructure that develops as a joint is deformed in sreep in shear at $4 \times 10^{-8} \mathrm{sec}^{-1}$ at $75^{\circ} \mathrm{C}$. The deformation is again localized to colony boundaries, however, this time without the presence of the parallel deformation band that characterizes deformation at faster strain rates. The deformation appears localized only to cnlony boundaries, specifically those that are roughly aligned with the direction of loading to yield a continuous deformation path along the direction of maximum shear.

Ternary Alloys

In Figures 22 and 23 the same comparison is made for the $\mathrm{Bi}$ and $\mathrm{Sb}$ alloys. In both cases the deformation patterns observed are highly nonuniform, deformation is concentrated in a narrow band parallel to the copper-solder interface. In both cases, a comparison of the deformation pattern with the corresponding polished microstructure, reveals that a "new" coarsened microstructure has evolved at the site of maximum deformation. The new microstructure is uniform and equiaxed and does not resemble the initial as-solidified eutectic colony structure present prior to deformation.

The microstructure and deformation patterns of the $\mathrm{Cd}$ - and In-alloyed solders are shown in Figures 24 and 25. No single plane of maximum deformation is apparent. The deformation patterns are significantly more homogeneous across the entire width of the solder joint when compared with the binary, Sb-, and Bi-alloyed solders. Examination of the associated microstructures reveals that no significant microstructural changes occur as the joint is deformed in creep. Samples crept at high temperatures exhibit some 
homogeneous coarsening of the as-solidified microstructure, wowever, no local microstructural changes such as those observed with the other alloys are apparent.

\section{Microstructural Evolution During Themal Fatigue}

Specimens of the configuration shown in Figure 12 were cycled between a hot, $125^{\circ} \mathrm{C}$, and a cold, $-55^{\circ} \mathrm{C}$, temperature bath. The microstructural evolution was monitored as a function of thermal cycles. In each case, specimens were thermally cycled, removed, polished and examined microscopically and returned for further cycling. The microstructural evolution that occurs as a function of thermal cycles appears in Figures 26-28 for the binary, Cd, and In alloys. (The microstructures are of a solder joint whose location relative to the center of the specimen translates into a nominal shear strain of $23 \%$.) Figure 26 illustrates the microstructural changes that occur in a $60 \mathrm{Sn}-40 \mathrm{~Pb}$ solder joint as it is cycled from $-55^{\circ} \mathrm{C}$ to $125^{\circ} \mathrm{C}$. The left-most image is the initiai microstructure, subsequent images represent the same spot in the specimen with increasing number of thermal cycles. The initial microstructire is the classic eutectic structure described earlier consisting of eutectic colonies made up of alternating phase regions of the $\mathrm{Sn}$ - and $\mathrm{Pb}$ - rich phases. As the cycling proceeds, the shear deformation concentrates into bands that are clearly marked by an associated rapid microstructural coarsening. The band of coarsened material traverses the initial microstructural features parallel to the $\mathrm{Cu} /$ solder interface, along the direction of maximum shear. After 1700 cycles, cracking of the solder joint is clearly visible within this coarsened band. Higher magnification SEM images of the coarsened band, Figure 29, clearly show its definition along with the equiaxed and coarsened individual $\mathrm{Sn}-$ and $\mathrm{Pb}-$ rich phase grains. As shown in Figure 26, failure occurs exclusively through this coarsened material.

Surface relief examinations of thermally fatigued ternary solder joints reproduce the relatively uniform deformation patterns seen under creep loading conditions. After a light 
polish, the microstructures that evolve as a function of thermal cycles for the In and $\mathrm{Cd}$ alloys can be seen in Figures 27 and 28. A thermal fatigue life comparison between the simple binary eutectic structures and the degenerate ternary alloys reveals the enhanced fatigue resistance of the latter alloys. For a nominal shear strain of $23 \%$, cracks first appear at 1700 cycles in the binary alloy, at 2300 cycles for the $\mathrm{Cd}$ alloy and at 3000 cycles for the In alloy. In Figure 30 a comparison of the three different compositions after 3000 thermal cycles at a nominal shear strain of $15 \%$ appears. The $60 \mathrm{Sn}-40 \mathrm{~Pb}$ joint is clearly cracked and both the In and $\mathrm{Cd}$ alloys appear intact. The cracking in the $60 / 40$ solder is, as expected. confined to the coarsened band, and the coarsened band is clearly visible and clearly microstructurally distinct from the remaining joint material. However, unlike the creep deformation, the thermal fatigue deformation does results in a coarsening of the solder microstructures. But, in contrast to the $60 / 40$ alloy, the coarsening is global and not confined to a band near a joint interface. Figure 31 shows a comparison of the binary, $\mathrm{Cd}$ and In solder joints after 3000 cycles at a nominal shear strain of $23 \%$. All joints have failed. The coarsening is joint wide in the ternary alloys unlike the localized coarsening that is characteristic of the binary alloy. 


\section{DISCUSSION}

The purpose of this work is to understand the role of the solder microstructure and its associations with the mechanisms of thermal fatigue and related deformation modes. A first step is an understanding of the microstructure/property relationship of the $\mathrm{Pb}-\mathrm{Sn}$ material, especially $\mathrm{Pb}-\mathrm{Sn}$ processed as a solder joint in an electronic device. Creep is an important deformation mode during the thermal fatigue cycle and, as will be shown later, reproduces the failure mechanisms of thermal fatigue. In this work, a study of creep behaviour is used to determine the microstructural mechanisms of solder joint failure and eventually paths towards their defeat. As will be discussed, solder joint failures under high temperature shear deformation - i.e. creep and thermal fatigue - are intimately related to the inherent mechanical inhomogeneity and instability of the as-solidified $\mathrm{Pb}-\mathrm{Sn}$ solder microstructures and suggest that small compositional changes to the solder may be beneficial. Potential alloying elements are identified and evaluated in both creep and thermal fatigue experiments.

\section{Microstructures}

The details of the eutectic $\mathrm{Pb}-\mathrm{Sn}$ solidification greatly affect the final microstructure, and thus the mechanical propicties. The possible microstructures range from the long range lamellar phase arrangements to the small features of the degenerate dispersed structures; the mechanical properties vary accordingly. Mechanically, the strongest microstructures are those that possess long range perfection and regularity of the phase to phase arrangement, e.g. the lamellar or rod-like morphologies. The areal extent of such an arrangement defines the eutectic colony, which is the crystallographic equivalent of a grain in a single phase material. Dislocation motion through such a colony is made difficult by the necessity to traverse many crystallographically matched phase boundaries, and the necessity to traverse regions of body-centered-tetragonal Sn phase (a crystallography with 
especially difficult dislocation mobility). Deformation of a multicolony structure is more easily accommodated at the eutectic colony boundaries or in more microstructurally degenerate regions where the strengthening mechanisms associated with the long-range phase to phase arrangement are less effective. Solder joints such as those studied here and those routinely e:" countered in service, consist of eutectic colonies and contain both lamellar and degenerate eutectic material. The many different microstructural features observed are consistent with the complex and random nature of solder joint solidification. Since each morphology is associated with its own mechanical response, the nonuniform colony microstructures of a solder joint predict an inhomogeneous deformation response.

As will be discussed later, this inherent inhomogeneity of the as-solidified microstructure and associated inhomogeneous response to deformation is intimately related to the failure mechanism in creep and thermal fatigue.

\section{Creep Data}

The high solder homologous temperatures and slow strain rates encountered during service of a solder joint imply that creep is an important deformation mode. A study of the creep response of a solder joint is thus warranted. In fact, the reasons for a creep study are twofold. First, an empirical representation of the creep behaviour is necessary in the construction of analytical models that incorporate creep deformation into the prediction of solder joint fatigue life. And, since, creep is in fact a subset of the thermal fatigue cycle, an understanding of the metallurgical mechanisms operative during creep, from microstructural observations and direct comparison of the empirical values measured here with already existing data on similar deformation modes, may give insight into the metallurgical mechanisms operative during thermal fatigue and thus indicate paths towards improved solder alloy development. 
We begin with a discussion of the measured parameters that describe creep deformation.

To investigate the predominant deformation mechanisms the steady-state creep data of an alloy system are usually represented by the equation

$$
\frac{d y}{d t}=A \tau^{n} e^{-E_{a} / k T},
$$

where $\frac{d \gamma}{d t}$ is the steady-state shear strain rate and $\tau$ is the shear stress [e.g. 24,42-49]. $E_{a}$ is the activation energy associated with a particular creep deformation mechanism; $n$, the stress exponent, is a semi-empirical constant representing the stress dependence of a given deformation mechanism; the constant $\mathrm{A}$ includes material specific information including a parameter describing the microstructure. In this representation, it is believed that, within a wide strain rate/stress regime, there exist regions of constant $n$ and $E_{a}$ values within each of which a different deformation mechanism dominates. As an example, conventional dislocation climb controlled plasticity in most materials is associated with a stress exponent in the range 4-10, an activation energy for creep deformation equal to that of self diffusion and no grain size dependence. Superplastic deformation is characterized by a stress exponent in the range of two, an apparent activation energy equal to the activation energy of grain boundary diffusion, and an inverse grain size dependance.[42-44,49]

Within a single material, several different deformation mechanisms may sequentially operate over a wide enough range of deformation conditions.[42,43,50,51] For example, the $\mathrm{Pb}-\mathrm{Sn}$ system, at elevated temperatures, is known to deform according to conventional (dislocation climb controlled) plasticity at high stresses, superplastically at intermediate stresses and by diffusional mechanisms such as Cobble or Nabarro creep mechanisms at very low stresses. $[46,47,48,63]$ Superplastic deformation of the eutectic Pb-Sn system has been extensively studied and the values of these constant are well known. The 
microstructures which exhibit superplasticity are not those of the as-cast material, but rather those microstructures that result after a mechanical working of the as-cast alloy, i.e. a recrystallized microstructure that is uniformly fine grained and equiaxed [23,24,52-61]. Superplasticity of the recrystallized $\mathrm{Pb}$-Sn microstructure has been observed for strain rates between $10^{-7}$ to $10^{-4} \mathrm{sec}^{-1}$ with a stress exponent $\sim 2[23,24,52-60]$ and activation energy on the order of $50 \mathrm{~kJ} /$ mole $(12 \mathrm{kcal} / \mathrm{mole}$ ) (a favorable agreement with the activation energy for grain boundary diffusion) $[24,53,54,56,58]$. Conventional plasticity in the eutectic $\mathrm{Pb}$ $\mathrm{Sn}$ material, e.g. deformation in other strain rate/stress regimes or deformation of nonsuperplastic microstructures, is associated with a stress exponent of $-6-7$ and an activation energy of $\sim 84 \mathrm{~kJ} / \mathrm{mole}(20 \mathrm{kcal} / \mathrm{mole})[24,45,52,62-65]$.

The creep data presented here, $n \sim 6$ and $E_{a} \sim 84 \mathrm{~kJ} / \mathrm{mole}(20 \mathrm{kcal} / \mathrm{mole})$, indicate that conventional plasticity mechanisms are rate controlling in the steady-state deformation of the as-solidified eutectic material in a joint configuration in the strain rate/stress regime $10^{-4}$ $\sec ^{-1}$ to $10^{-8} \mathrm{sec}^{-1}$ and $10-100 \mathrm{MPa}$. These values are in good agreement with values reported elsewhere on the creep deformation of this material in bulk form. Since the microstructures of the bulk specimens and of the experimental solder joint studied here are similar, this agreement is expected.

Recent work on rapidly solidified solder joints, i.e. solder joints that possess very degenerate microstructures, indicate a stress exponent close to two $[66,67]$ and an activation energy representative of grain boundary diffusion. These values are significantly lower than those seen here and, also, lower than those expected based on previous work. These values are, in fact, in the range usually associated with superplastic deformation. The exceptional plasticity that characterizes superplastic deformation is attributed to grain boundary sliding and grain boundary diffusion mechanisms. As such, superplasticity is associated with stable, very fine, equiaxed micrustructuies that possess a high giain 
boundary area. Superplastic microstructures are thus usually not as-cast microstructures, but rather those that result after a thermo-mechanical treatment to homogenize and refine the grain size and distribution, i.e. recrystallized microstructures. However, with very rapidly solidified solders, such as those in the work of Grivas et al. [66], the long range lamellar structures that characterize the more moderately cooled solders are replaced with finer more degenerate and equiaxed features. These degenerate features morphologically and crystallograp.ically resemble those associated with superplastic deformation. The data to date indicate that they in fact deform accordingly. Superplasticity in a rapidly solidified $\mathrm{A} / \mathrm{Zn}$ microstructure has previously been demonstrated $[49,66]$; these recent data indicate similar behaviour in the $\mathrm{Pb}-\mathrm{Sn}$ system.

The measured values of $n$ and $E_{a}$ are less meaningful if more than one mechanism is operative and no single mechanism is strongly dominant. In this case, the velue of the constant must reflect the competing mechanisms. For example, during the transition region from superplastic to conventional dislocation climb controlled deformation, no single mechanisms dominates and the values of $\mathrm{n}$ are somewhere between two and six, those values normally associated with conventional plasticity and superplasticity in eutectic $\mathrm{Pb}$ $\mathrm{Sn}$. A similar reasoning maybe used to infer intermediate values of stress exponents and activation energies of microstructures that possess a partial superplastic character.

Other works on the creep deformation characteristics of solder joints report values of the stress exponents for solder joints in the range $2-6 .[67-70]$ The different joint geometries and joint processing techniques used in each of these experiments will most likely result in a variety of solder microstructures. These creep data are not accompanied by microstructural information, and thus a correlation of microstructure and stress exponent is not possible. An explanation may lie in the changing areal extent of the eutectic microstructure's degeneracy with various manufacturing procedures. A more degenerate 
microstructure is expected to have a larger superplastic component in creep deformation and thus a lower stress exponent.

There are no similar data available for the ternary alloys to allow a direct comparison. However, a comparison among the alloys studied shows that the values of $n$ and $E_{a}$ for the In and $\mathrm{Cd}$ alloys are slightly lower than those associated with the other alloys. Similar to the rapidly solidified joints, this behaviour may be rationalized solely through the microstructural changes caused by the third element addition. The Bi- and Sb-alloyed solders exhibit stress exponents similar to those of the simple binary alloys. These two alloys also possess the microstructures that most resemble those of the simple binary alloy. The In and Cd alloys microstructures contain the least amount of lamellar eutectic material and the most degenerate, equiaxed material. In other words, these microstructures, much more than the others, resemble, at least locally, superplastic microstructures. Similar to the lower stress exponents that characterize deformation of rapidly solidified solder joints, the lower values of the stress exponents of the ternary alloys may reflect the altered microstructure and a superplastic component in their deformation.

\section{Deformation During Creep}

Binary Alloys

Thermal fatigue failures have long been associated with the appearance of a coarsened solder microstructure in the vicinity of the joint failure $[17,18,68-75]$. However, the origin and relationship of this coarsening phenomenon to the mechanisms of thermal fatigue are not understood. Creep deformation, as shown here, reproduces a similar failure and allows for a sequential and detailed study of this phenomenon. Based on these observations, the mechanism of coarsened band initiation and growth is proposed and is used to identify metallurgical paths towards its defeat. 
The mechanism of initiation of the coarsened band seems straightforward. The joint solder microstructure deforms inhomogeneously; deformation occurs primarily along colony boundaries where the softest material is found. The inhomogeneity of the shear strain is further enhanced in the vicinity of a stress concentration. It is well known that $\mathrm{Pb}-\mathrm{Sn}$ alloys are unstable with respect to recrystallization if sufficiently worked at sufficiently high homologous temperatures or if exposed to high temperature after deformation. The inhomogeneous shear strain that develops during deformation creates regions of concentrated plastic deformation. This effect is greatest near the principal stress concentration within the joint configuration, and the eutectic recrystallizes there to relieve the accumulated deformation (Figure 20 shows the location of the stress concentration in this joint geometry, a comer in each of the four lateral free surfaces [41]).

The mechanism of growth of this pocket of recrystallized material into the observed bands also seems straightforward. Once a recrystallized region has formed it grows through the progressive recrystallization of the deformed material nearby. Since the recrystallized material is soft compared to the material surrounding it, it behaves mechanically like a narrow crack. The applied stress is a simple shear, and the associated strain field is characteristic of a mode II crack. The plastic strain field for a mode II crack has been solved for a Von Mises material by McClintock, et al. [76] and is diagrammed in Figure 32. Note that the deformation field is highly elongated along the direction of the applied shear and thus tends to confine the deformation to a thin region containing the crack parallel to the direction of crack growth, i.e. the direction of applied shear. It follows that recrystallization and coarsening will always occur at the periphery of the recrystallized region in the plane of the applied shear since this is the most highly deturmed material. Thus the recrystallized band tends to remain plane and narrow while it extends itself along a shear plane (parallel to the $\mathrm{Cu} /$ solder interface), as is observed. 
Inhomogeneous shear deformation, resulting from the inhomogeneity of the as-solidified microstructure, triggers inhomogeneous coarsening of the eutectic microstructure that is concentrated in bands of maximum shear. Since the microstructure softens as it coarsens, shear deformation concentrates in the coarsened regions, which therefore coarsen more rapidly. Eventually, the accumulated strain leads to cracks within the coarsened material, and the joint ultimately fails.

The more tortuous path of the coarsened band in the more slowly strained specimens, Figure $21\left(10^{-8} \mathrm{sec}^{-1}\right)$, may be reasoned as follows. Again, creep deformation initiates an inhomogeneous mechanical response in the joint solder. However, the slow strain rates allow for relief and recovery mechanisms to operate and thus reduce the local strain levels enough so that the growth of the coarsened band becomes sensitive to the microstructure in its path. Growth of the coarsened band thus occurs along the soft material at those colony boundaries that are aligned with the direction of maximum shear.

The formation of coarsened bands is the result of the inhomogeneity of the solder microstructure, the associated inhomogeneity in mechanical response, and the microstructural insurabilities this creates. The steady-state creep data obtained from the solder joints indicate normal plasticity, as expected, and do not give insight into the details of the failure mechanism. However, the onset of the microstructural instability is visible in the creep curve as the transition to the tertiary stage. The more relevant parameter is the extent of the steady-state deformation which appears to be a measure of the solder's resistance to the initiation of the recrystallization and coarsening creep failure mechanism.

\section{Towards More Fatigue Resistant Solders}

Examination of "real" thermally fatigued solder joints of similar microstructures reveais that fatigue failures are usually preceded by the formation of a region of significantly coarsened 
material at the site of eventual failure $[18,20,68-75]$. It thus seems reasonable to assume that similar mechanisms are operative in creep as in thermal fatigue: joint failure is caused by a localization of strain resulting from the inhomogeneity of the as-solidified microstructure driving a local recrystallization and coarsening, thus softening, of the microstructure in which cracks easily initiate and propagate to cause failure. The proposed analysis suggests that the critical need is to prevent the formation of the coarsened bands and indicates that the extent of steady state deformation under creep conditions is a possible measure of the solder's resistance to the failure mechanism. Furthermore, two specific metallurgical paths toward the design of fatigue resistant solder alloys are indicated. The first is to produce a solder that deforms more homogeneously in shear, thereby suppressing the concentrated shear that drives the recrystallization and coarsening. The second is to minimize the rate of recrystallization and coarsening in the deformed material. The addition of a third element potentially achieves both of these desired effects.

The third element influences the solidification behaviour and thus results in a microstructure that contains a smaller volume of regular eutectic material, and thus a microstructure that deforms more homogeneously. The long range regularity of the aligned eutectic material arises from the stability of the advancing liquid/solid interface. In solution, the third element, acting analogously to an impurity in a simple binary alloy, will result in regions of local supercooling ahead of the solid/liquid interface as it is rejected out of the solidifying material. The local supercooling will destabilize the liquid/solid interface and results in a cellular more degenerate and irregular structure. Alternately, if the third element reacts to form a new phase, e.g. a $\mathrm{Pb}$ or $\mathrm{Sn}$ intermetallic phase, the particles may act as nucleation sites for further eutectic solidification. The increased nucleation density will result in a smaller eutectic colony size and thus a greater amount of degenerate irregular colony boundary material. The mechanical response of both such structures will be more uniform since there are more "soft" areas to accommodate the deformation. 
Additionally, the third element addition may affect the inherent stability of the material with respect to recrystallization and coarsening. In single phase systems, the aduition a sufficient amount of an appropriate element is well known to affect the rate of recrystallization; two possible mechanisms are briefly mentioned below. Recrystallization requires nucleation of strain free grains and the subsequent migration of these new grain bo'sndaries to consume and replace the old worked material. An inhibition of this phenomenon is possible if the grain boundary mobility is reduced. An added element in solution will tend to migrate to interfaces and grain boundaries to minimize misfit and thus the free energy of the system. This solute atmosphere must be dragged by the boundary which can move only as fast as the solute atoms can migrate, thus decreasing its velocity. Theoretically, this drag mechanism is most effective with elements that have a strong attraction for grain boundaries and those that have low diffusivities. An added element that forms a second phase is also beneficial in inhibiting recrystallization. Similar to the solute drag effect, a finely dispersed second phase will also exert a retarding force on grain boundary growth.

The identification of potential alloying elements used in this work is based on a survey of early metallurgical studies of the pure and alloyed $\mathrm{Sn}$ and $\mathrm{Pb}$ metals.[77-80] Of particular interest are thermal fatigue related phenomena, including recrystallization, creep and coarsening. The elements used as additives in this work were thus identified based on their documented ability to alter creep and recrystallization characteristics of the two constituent phases. The manufacture of solder joints is such that the alloy must be used in the assolidified state, so post solidification processing steps are prohibited. A fine uniform distribution of a second dispersed phase is hard achieve, thus only those elements that are expected to go into solution were investig ated. The elements thus identified and evaluated include In, Cd, Bi and Sb. 


\section{Ternary Solders}

In contrast to the simple binary alloys, the high temperature creep deformation of the In and $\mathrm{Cd}$ ternary solders is associared with the development of relatively uniform deformation patterns. Surface relief observations, such as those in Figure 24 show that the deformation in the degenerate microstructures of the In- and Cd-containing alloys is accommodated over a much greater area than in the case of the simple normally cooled binary eutectic structures. These observations are consistent with the greater volume of degenerate soft material in the In- and Cd-alloyed microstructures.

Furthermore, the coarsened band formation associated with creep in the lamellar eutectic structures does not form in these degenerate, more uniformly deforming morphologies. The addition of the third element has altered both the initial microstructure and, potentially, its resistance to recrystallization. It is difficult to separate these effects since the microstructural change alone can explain these observations. The absence of the recrystallized band may be simply due to insufficient driving force for recrystallization. Since the deformation is accommodated over a much larger area, local strain intensities are expected to be lower and may never reach the levels needed to úrive a recrystallization. Or, as was discussed earlier, the possibility of a superplastic component in the deformation may also play a role. Superplastic deformation, by definition, occurs without the amount of stored energy, in the form of dislocations, that characterizes conventional plastirity mechanisms. Since it is the stored energy that drives a recrystallization, a superplastic component in the deformation would have to reduce the rate at which damage accumulates and thus the impetus for recrystallization.

Additionally, the strain range of steady-state deformation in the ternary alloys is larger than that of the binary solder: steady-state deformation accounts for 6-8\% strain in the binary 
solder joints and $12-15 \%$ strain in the ternary solder joints. Again, a superplastic component in the deformation may account for the increased elongation in secondary creep.

The creep behaviour of the binary solder joints along with the observations on the In- and Cd-alloyed solders, indicate that the coarsened band formation accelerates joint failures. Since thermal fatigue failures also initiate with the development of a coarsened microstructure at the failure site, these results suggests that the inhibition of a coarsened microstructure could lead to a longer fatigue life. Further investigation of the ternary solders is certainly warranted.

\section{Thermal Fatigue of Solder Joints}

As shown in Figure 26, the microstructural changes associated with thermal fatigue deformation of the experimental solder joints studied here are similar to those observed under creep deformation. Deformation is highly localized and failure is associated with a band of microstructurally coarsened material. Figure 29 clearly shows the detail of the microstructure within the coarsened band and its definition relative to the microstructure elsewhere in the joint. Grain boundary contrast, due to etching, is clearly evident in the coarsened band where the uniform grain size and shape distribution of the two phases and its striking difference from the parent microstructure again indicate a recrystallization and coarsening. This is not the case in the remaining joint microstructure. Consistent with the assumption that the entire colony is a single uid continuous crystallographic unit and is essentially unaffected by the deformation, no grain boundary contrast (due to etching) is visible within the colony, as was the case in the crept specimens.

The microstructural observations on the thermally fatigued specimens are representative of "real" solder joint thermal fatigue failures [68-75], and are in good agreement with the changes observed during creep. In both deformation modes, inhomogeneous deformation, 
resulting from the highly localized mechanical response of the colony structure, leads to microstructural instabilities that initiate joint failure. Under creep deformation, these instabilities are prevented by appropriate microstuctural changes caused by a third element addition to the binary $\mathrm{Pb}-\mathrm{Sn}$ solder. The more homogeneous creep deformation response of the more uniform In and $\mathrm{Cd}$ solder microstructures result in a longfr steady-state deformation region and failure occurs without the microstructural changes seen in the simple binary solders.

The hehaviour of the $\mathrm{Cd}$ and In ternary alloys under thermal fatigue conditions is somewhat different. The net effect on fatigue life is to increase the number of cycles (an improvement of at least 50\%) before cracks appear, and failure occurs by an apparently different mechanism. The more mechanically uniform microstructures allow for more uniform deformation and lead to a coarsening of the eutectic material. The extent of this coarsening is joint wide, consistent with the extent of deformation. This is a strain enhanced coarsening since the solder near the center of the specimen, where the strain is zero, shows no significant microstructural changes with fatigue cycles. Figure 33 shows the microstructure of a thermally fatigu i In specimen. On the left, is a region that experienced a nominal $20 \%$ shear strain, and on the right is a region from the center of the specimen, i.e. zero strai , that experienced only temperature cycling. The coarsening is associated only with the strain/temperature combination. The coarsening initiates in the coarser degenerate material at the colony boundaries and with cycling consumes the lamellar eutectic material in the colony interiors. In these ternary solders, a recrystallization is not immediately obvious. The microstructural changes occur very gradually, without the striking immediate changes observed in the simple binary alloys.

Third elements were added with the intent of altering the as-solidified microstructure and enhancing recrystallization and coarsening resisiance. The binary solder microstructure 
was altered and resulted in a more uniform deformation response. The rapid coarsening of the ternary solder under thermal fatigue conditions makes it clear that grain boundary mobility was not significantly retarded und ar these thermo-mechanical conditions. It should be noted, however, that the very high homologous solder temperatures $\left(125^{\circ} \mathrm{C}\right.$ corresponds to 0.86 of the solder's melting point) encountered during the fatigue cycle would require an extremely effective grain boundary pinning merhanism. Perhaps a lower maximum temperature would allow the third element to interfere with the coarsening behaviour; this is an area of further study.

The enhanced fatigue lives of the ternary solder joints are attributed to the more degenerate, mechanically uniform initial microstructures which do not result in the strain localization that characterizes the creep and thermal fatigue response of the binary near-eutectic $\mathrm{Pb}-\mathrm{Sn}$ solders. The deformation in the ternary solders is sufficient to show a significant strain enhanced coarsening, however the effect is global over the entire solder joint width. Again, as in creep deformation, the local strain levels are thus significantly reduced along with the rate of damage accumulation thus accounting for the increased fatigue life. 


\section{CONCLUSIONS}

Increased solder joint reliability requires the design of accelerated test to accurately predict fatigue live : and the development of new fatigue resistant solders. Both issues are. addressed in this work. An accelerated test is valid only if it accurately reproduces the fatigue failure mechanisms on: an accelerated laboratory time scale, and thus depends critically on the identification and understanding of the operative mechanisms. A microsıructural failure mechanism, based on observations of creep and thermal fatigue failures, is proposed here. Based on this understanding, metallurgical changes that should help defeat these failure mechanisms are identified and evaluated. The results indicate a significantly enhanced thermal fatigue resistance of a $58 \mathrm{Sn}-40 \mathrm{~Pb}-2 \mathrm{In}$ solder. Furthermore, this work illustrates the value of a creep test to evaluate solder materials and confirm that conventional plasticity deformation rnechanisms control deformation in steady-state creep.

In near eutectic $\mathrm{Pb}-\mathrm{Sn}$ solders failure under creep anci thermal fatigue deformation is intimately related to the as-solidified eutectic colony structure. In this type of microstructure, deformation is most easily accommodated in the degenerate material separating individual colonies. The relatively large colony size implies a small colony boundary area and thus very high strain localizations. The instability of the $\mathrm{Pb}-\mathrm{Sn}$ alloys is well documented; the as-solidified material readily recrystallizes with mechanical work at elevated temperatures to yield a much softer, equiaxed and fine-grained structure. The strain localization in the as-solidified solder joints initiates a local recrystallization within the joint. Since the recrystallized material is much softer, further localized deformation occurs ahead of the recrystallized material to drive a continuous recrystallization along the direction of shear. Eventually, cracking within the recrystallized and coarsened material leads to joint failure. 
The addition of a small amount of In and $\mathrm{Cd}$ changes the initial as-solidified microstructure. These ternary alloys possess microstructures with a significantly less defined colony structure and contain a higher fraction of degenerate material. The mechanical response of such microstructures is more uniform and prevents the high strain localizations that characterize the deformation of the simple binary alloys. The lower strain intensities reduce the rate at which damage accumulates within the joint to increase the extent of steady-state deformation under creep conditions and to significantly increase the cycles to cracking under thermal fatigue conditions. 


\section{REFERENCES}

1. M. McLean, Directionally Solidified Eutectics, The Metals Society, London (1983).

2. P.G. Shewmon, Transformations in Metals, J. Williams Book Co., OK (1983).

3 R. Elliott, Eutectic Solidification Processing Butterworths, London (1983).

4. J.D. Verhoeven, D.P. Mourer and E.D. Gibson, Met Trans. A, 8A (1977) p.1239.

5. J.D. Hunt, J. Inst. Met. 24 (1964) p.125.

6. R.H. Hopkins and R.W. Kraft, Trans. AIME, 242 (1968) p. 1627.

7. B. Labulle and C. Petipas, J. Cryst. Growth, 28 (1975) p. 279.

8. M.G. Blanchin, A. Guinier, C. Petipas and G. Sauvage, Acta Met., 20 (1972) p.1251.

9. M. Cagnon, M. Suery, A. Eberhardt and B. Baudelet, Acta Met. 25 (1977) p. 71.

10. T.H. Alden, Treatise on Materials Science and Technology, 6, Plastic Deformation, R.J. Arsenault, ed., Academic Press, San Francisco, (1975), p.225.

11. R.W. Kraft, J. Met., 2 (1966) p.192.

12. L.K. Quan, "Tensile and Shear Behaviour of Alloys Sn-Pb Solder Joints", M.S. Thesis, University of California, Berkeley, (1988).

13. J.P. Chilton and W.C Winegard, J. Inst. Met., 89 (1960) p. 162.

14. H.W. Weart and D.J. Mack, Trans. Met. Soc. AIME, 10 (1958) p.664.

15. D.Frear, D. Grivas, J. W. Morris, Jr. J. Elect. Mat., 16 (1986) p. 181.

16. D.Firear, D. Grivas, and J.W. Morris, Jr., J. Elect. Mat., 16 (1987) p.181.

17. D.Frear, D. Grivas, and J.W. Morris, Jr.. J. Met., 40 (1988) p.18.

18. D. Tribula, D. Grivas, D.Frear and J.W. Morris, Jr., Weld. J. Res. Supp., 68 (1989) p.404s.

19. J.A. Eady and W.C. Winegard, Canı. Met. Quart., 103 (1971)p. 213.

20. R.W. Kraft, D.L. Albright, J.A. Ford, Trans. Met. Soc. AIME, 227 (1962) p.540.

21. H.E. Cline and T.H. Alden, Trans. AIME, 239 (1967) p.710. 
22. D.H. Avery and W.A. Backhofen, Trans. ASM, 58 (1965) p.551.

23. W.B. Morrison, Trans. AIME, 242 (1968) p.2221.

24. B.P. Kashyap and G.S. Murty, 50 (1981) p.205.

25. M. Frebel and B. Otte, Scripta Met., 2 (1975) p.1317.

26. L.D. Graham and R.W. Kraft, Trans. AIME 236 (1966) p.94.

27. M. Frebel, G. Dudek, W. Graf, M.N. Faridani, B. Otte, Ber. Bunsenges. Phys. Chem., 82 (1978) p.259.

28. J.D. Livingston, J.W. Cahn, Acta Met., 22 (1974) p.495.

29. M. Frebel, G. Dudek, Mat. Sci. Eng., 32 (1974) p.125.

30. B.P. Kashyap and G.S. Murty, Met. Trans. A, 13A (1982) p.53-.

31. M. Fine and R.L. Dowdell, Trans. ASM, 37 (1946) p.245.

32. W.A. Baker, J. Inst. Met., 659(1939) p.277.

33. C.E. Pearson, J. Inst. Met., 54 (1934) p.110.

34. C.H.M. Jenkins, J. Inst. Met., 40 (1928) p.21.

35. Specimen courtesy of J. Maki, EMPF, China Lake, CA.

36. H.J. Rack and J.K. Maurin, J. Test. and Eval., 25 (1974) p.351.

37. F. Hargreaves, J. Inst. Met., 38 (1927) p.315.

38. F. Hargreaves, J. Inst. Met., 40 (1928), p.41.

39. F. Hargreaves , J. Inst. Met., 39 (1928) p.301.

40. F. Hargreaves and J. Hills, J. Inst. Met., 41 (1929) p. 257

41. F.K. Chen, "Applications of the Finite Element Method to the Plastic Deformation Analysis of Perforated Sheet Metals and the Process Simulation of Shape Rolling", Ph.D. Thesis, University of California, Berkeley, CA (1989).

42. J.E. Bird, A.K. Mukherjee, J.F. Dorn, Quantitative Relations Between Properties and Microstructure, Israel University Press, (1969).

43. A.K. Mukherjee, J.E. Bird, J.F. Dorn, Trans. ASM 62 (1969) p.155.

44. J. Weertman and J.R. Weertman Phusical Metallurgy, R.W.Cahn, P. Haasen, eds., Elsevier Science Publishers, (1983) p.1310.

45. M.L. Vaidya, K.L. Murty, and J.E. Dorn, Acta. Met., 21 (1973) p.1616.

46. F.A. Mohamed, K.L. Murty, J.W. Morris, Jr., Met. Trans., 4 
(1973) p.935.

47. R.L. Coble, J.App. Phys., 34 (1963), p. 1091.

48. F.R. Nabarro, Conference on the Strength of Solids, The Physical Society, London (1948), P. 75.

49. D. Grivas, Ph.D. Thesis, "Deformation of Superplastic Alloys of Relatively Low Strain Rates", University of California, Berkeley, CA (1979).

50. L.Lagneborg, Inter. Met. Rev., 17 (1972) p.130.

51. O.D. Sherby. P.M. Burke, Prog. Mat. Sci, 13 (1967) p.325.

52. S.W. Zehr and W.A. Backhofen, Trans. ASM, 61 (1968) p.300.

53. J.H. Schneibel, P.M. Hazzledine, J. Mat. Sci., 18 (1983) p.562.

54. A.E. Geckinli, C.R Barrett, J. Mat. Sci., 11 (1976) p.510.

55. G.S. Murty and B.P. Kashyap, Trans. Ind. Inst. Miet., 375 (1984) p.509.

56. F.A. Mohamed, T.G. Langdon, Phil. Mag. (1975)p. 697.

57. R.K. Yadava and K.A. Padmanabhan, J. Mat. Sci., 17 (1982) p. 2435.

58. B. Baudelet and M. Suery, J. Mat. Sci., I (1972) p.512.

59. B.P. Kashyap and G.S. Murty, Met. Trans. A, 12A (1981) p.1923

60. R.K. Yadava and K.A. Padmanabhan, Mat. Sci. and Eng., 37 (1979) p.127.

61. B.P. Kashyap, A. Arieli and A.K. Mukherjee, J. Mat. Sci., 20 (1985) p. 2662.

62. G.S. Murty, J. Mat. Sci., 8 (1973) p.611.

63. D. Grivas, M.S. Thesis, "Steady State Creep in Pb-Sn Eutectic Alloys", University of California, Berkeley, CA (1974).

64. R.W. Rohde and J.C. Swearengen, Trans ASIME, J. Eng. Mat. and Tech., 102 (1980) p.207.

65. R.C. Weinbell, J.K. Tien, R.A. Pollack, and S.K. Kang, J. Mat. Sci., (1987) p.3901.

66. D.Grivas and J.W. Morris, Jr., to be published.

67. M.C. Shine and L.R. For, Low Cycle Fatigue, ASTM STP 942, H.D.

Solomon, Ed., American Society for Testing and Materials, Philadelphia, (1988) p. 588.

68. H.D. Solomon, Brazing and Soldering, 11 (1986) p.68.

69. P.M. Hall, IEEE Trans., CHMT-12 (1987) p.556. 
70. N.F. Erike and B.I. Sandor, ASME publication 88-WA/EEP-12, (1988).

71. R.N. Wild, "Some Properties of Solder and Solder Joints", IBM Report no. 74 z000481, October 1975.

72. E.R. Bangs and R.E. Beal, Weld. Res. Supp. Weld. J., 54 (1978) p.377.

73. W.M. Wolverton, Braz.. and Sold., 13 (1987) p.33.

74. "Know Your Enemy: How to Stop Solder Joints form Cracking " Circ. Manuf., Nov. p. 10.

75. D. Frear, D. Grivas, M. McCormack, D. Tribula, J.W. Morris, Jr., Effect of Load and Thermal Histories of Mechanical Behaviour TMS (1987) p.113.

76. F.A. McKlintock and G.R. Irwin, "Plasticity Aspects of Fracture", ASTM STP 381 (1965) p.84 as referenced in Elementary Engineering Mechanics, D. Broek, Martinus Nijhoff Pub., (1983) p.99.

77. D. Hanson and E.J. Sandford, J. Inst. Met. 59 (1936) p. 159.

78. A.H. Sully, Metallic Creep and Creep Resistant Alloys, Butterworths, London, (1949).

79. L.M.T. Hopkins and C.J. Thwaites, J. Inst. Met. 54 (1953) p.181.

80. C.H. Jenkins, J. Inst. Met., 40 (1921) p.21. 


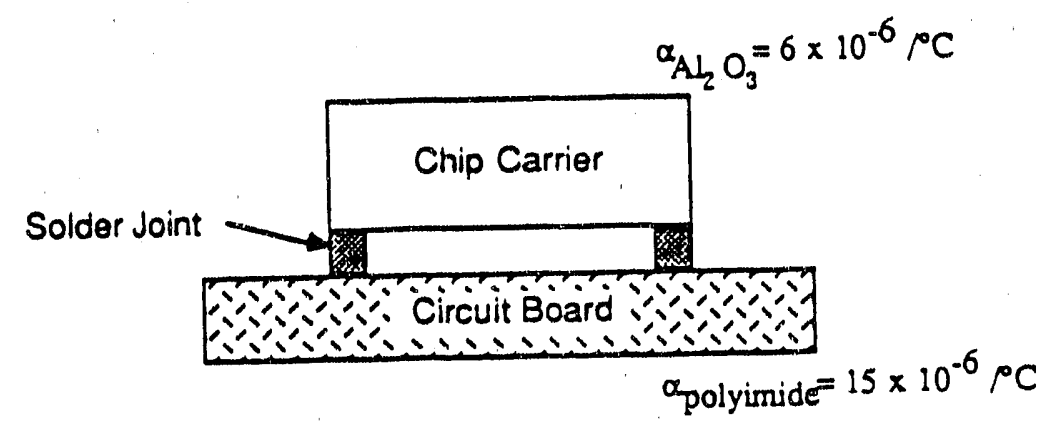

Electronic Package at Zero Strain

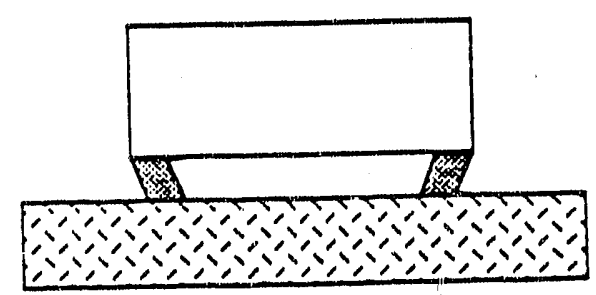

Electronic Package with Negative Temperature Excursion

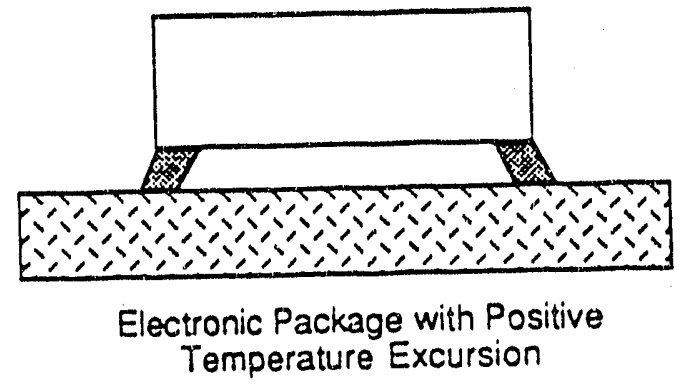

Figure 1. Schematic illustration of the shear that develops in a solder joint between chip and substrate with high and low temperature excursions. 


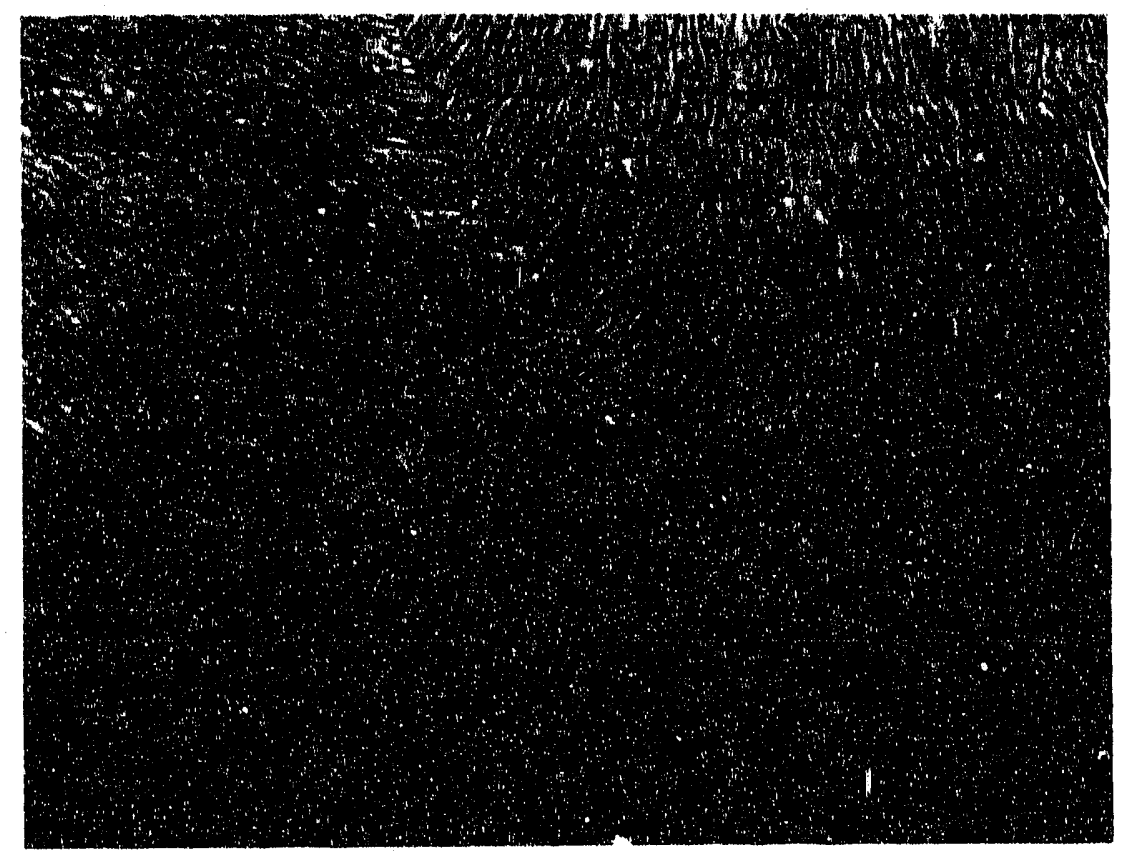

$25 \mu \mathrm{m}$

Figure 2. SEM micrograph of a eutectic $\mathrm{Pb}-\mathrm{Sn}$ solder slowly cooled from $250^{\circ} \mathrm{C}$. Slow cooling results in a highly lamellar structure as shown. In the figure above, two eutectic grains are seen. Each grain is distinguished by a specific direction of lamellar arrangement, and a distinct boundary delineates each grain. The light regions are the $\mathrm{Pb}-$ rich phase, the dark regions are the Sn-rich phase. XBB $877-5538$ 

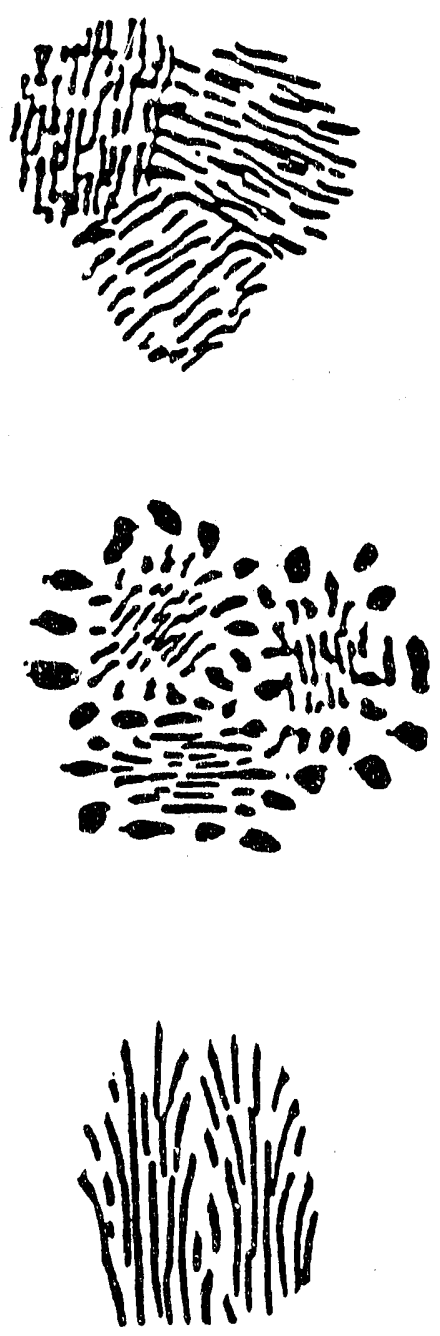

Figure 3. Schematic representations of several features of a eutectic microstructure:

(top) several lamellar grains showing distinct grain boundaries, (middle) several lamellar grains showing irregular degenerate material at the grain boundaries, (bottom) a single eutectic grain showing a colony substructure. 


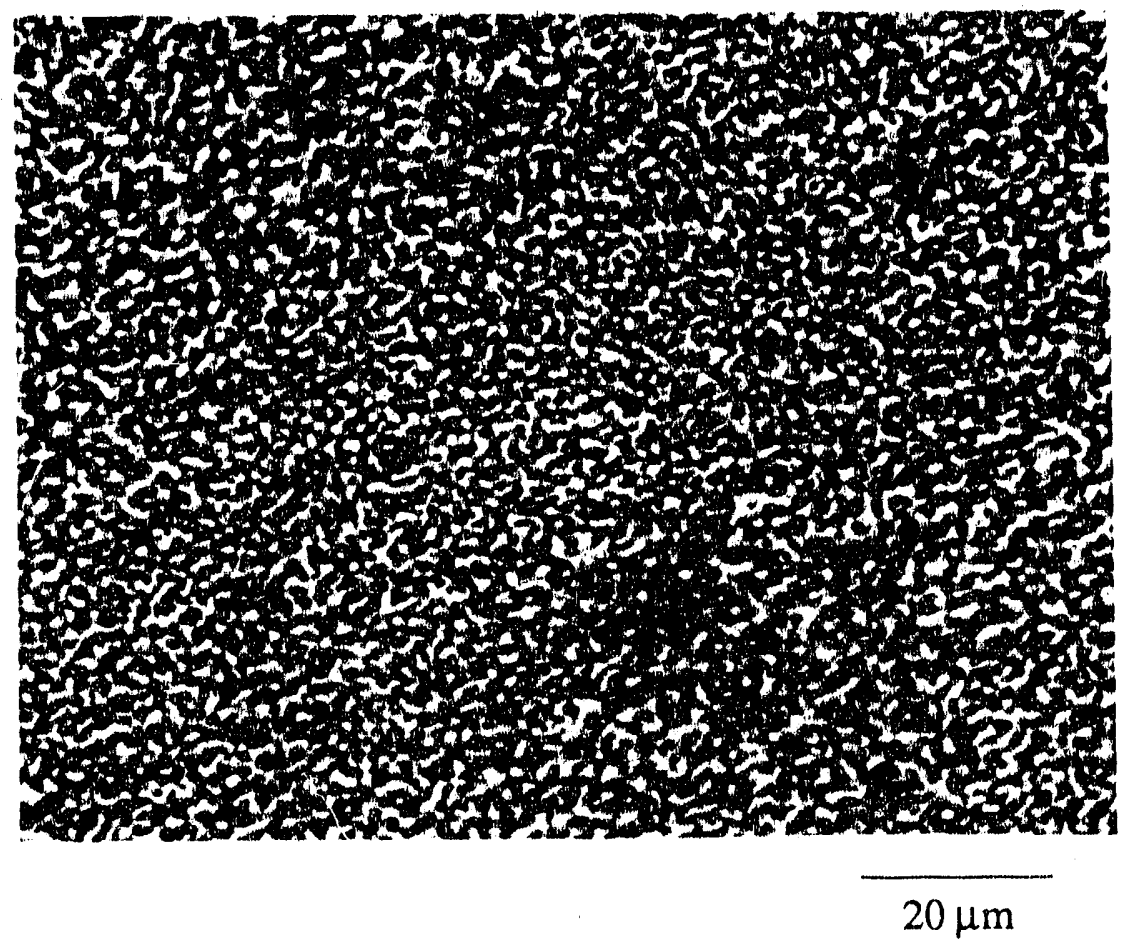

Figure 4. SEM micrograph of a eutectic $\mathrm{Pb}-\mathrm{Sn}$ alloy water quenched from $250^{\circ} \mathrm{C}$. The microstructure lacks the eutectic colony features characteristic of slower cooled specimens, and appears instead as a homogeneous dispersion of the $\mathrm{Pb}$-rich phase in a $\mathrm{Sn}$-rich matrix. The light regions are the $\mathrm{Pb}$-rich phase, the dark regions are the $\mathrm{Sn}$-rich phase. XBB $877-5538$ 


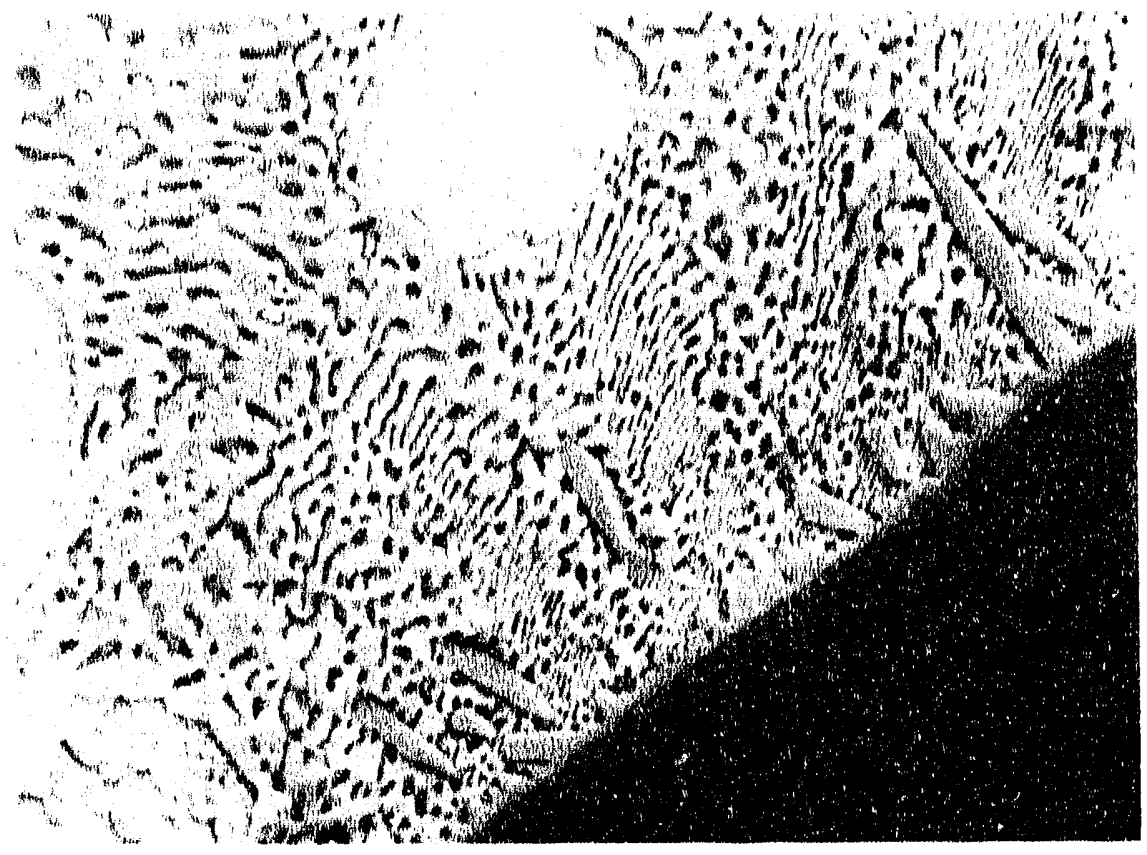

$10 \mu \mathrm{m}$

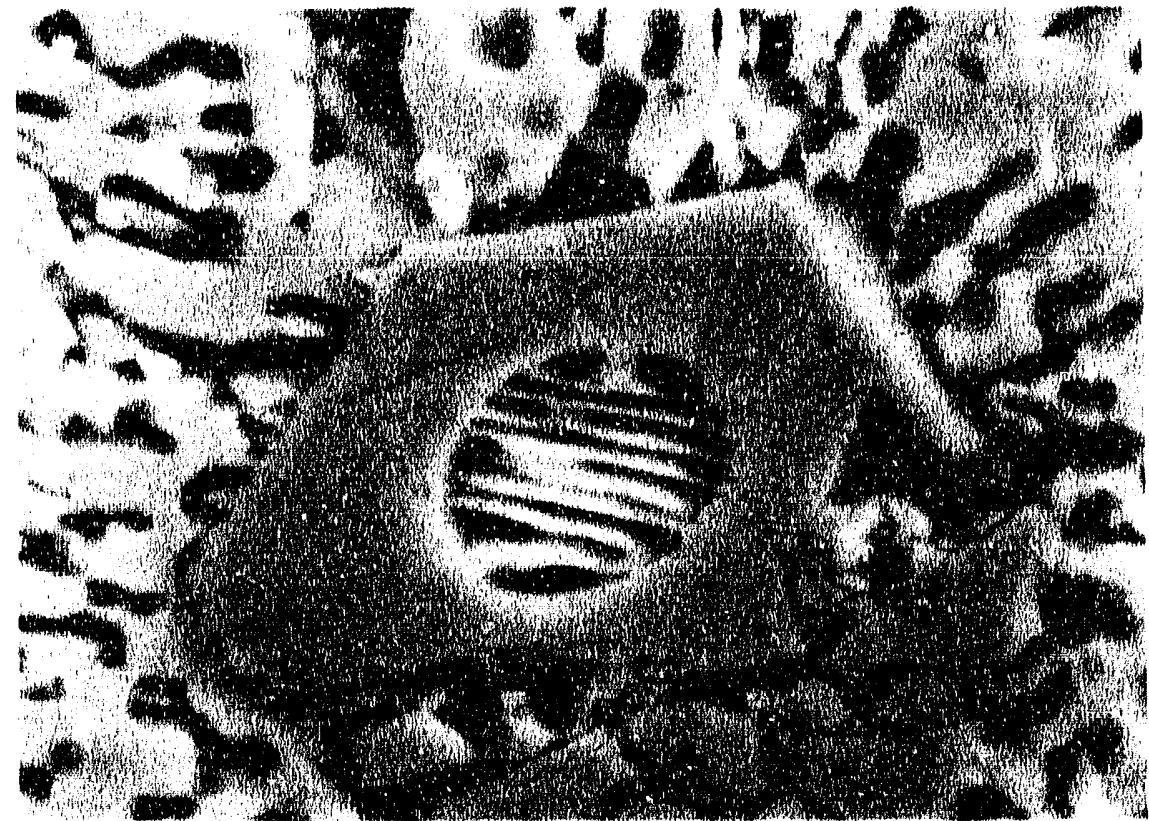

$2 \mu \mathrm{m}$

Figure 5. SEM micrograph of a polished $60 \mathrm{Sn}-40 \mathrm{~Pb}$ surface et hed to reveal details of the microstructures. (top) Interfacial intermetallics are clearly seen at the $\mathrm{Cu} /$ solder interface. The interfacial intermetallic phase is in fact a bilayer consisting of a $\mathrm{Cu}_{3} \mathrm{Sn}$ layer and a layer of $\mathrm{Cu}_{6} \mathrm{Sn}_{5}$ adjacent to the solder. (bottom) Detail of a $\mathrm{Cu}_{6} \mathrm{Sn}_{5}$ intermetallic particle found in the bulk solder joint material. These intermetallics originate at the $\mathrm{Cu} / \mathrm{solder}$ interface. Turbulence during solidification causes them to break off and locate within the bulk of the solder material. The light regions are the Pb-rich phase, the dark regions are the Sn-rich phase. XBB869-7448 


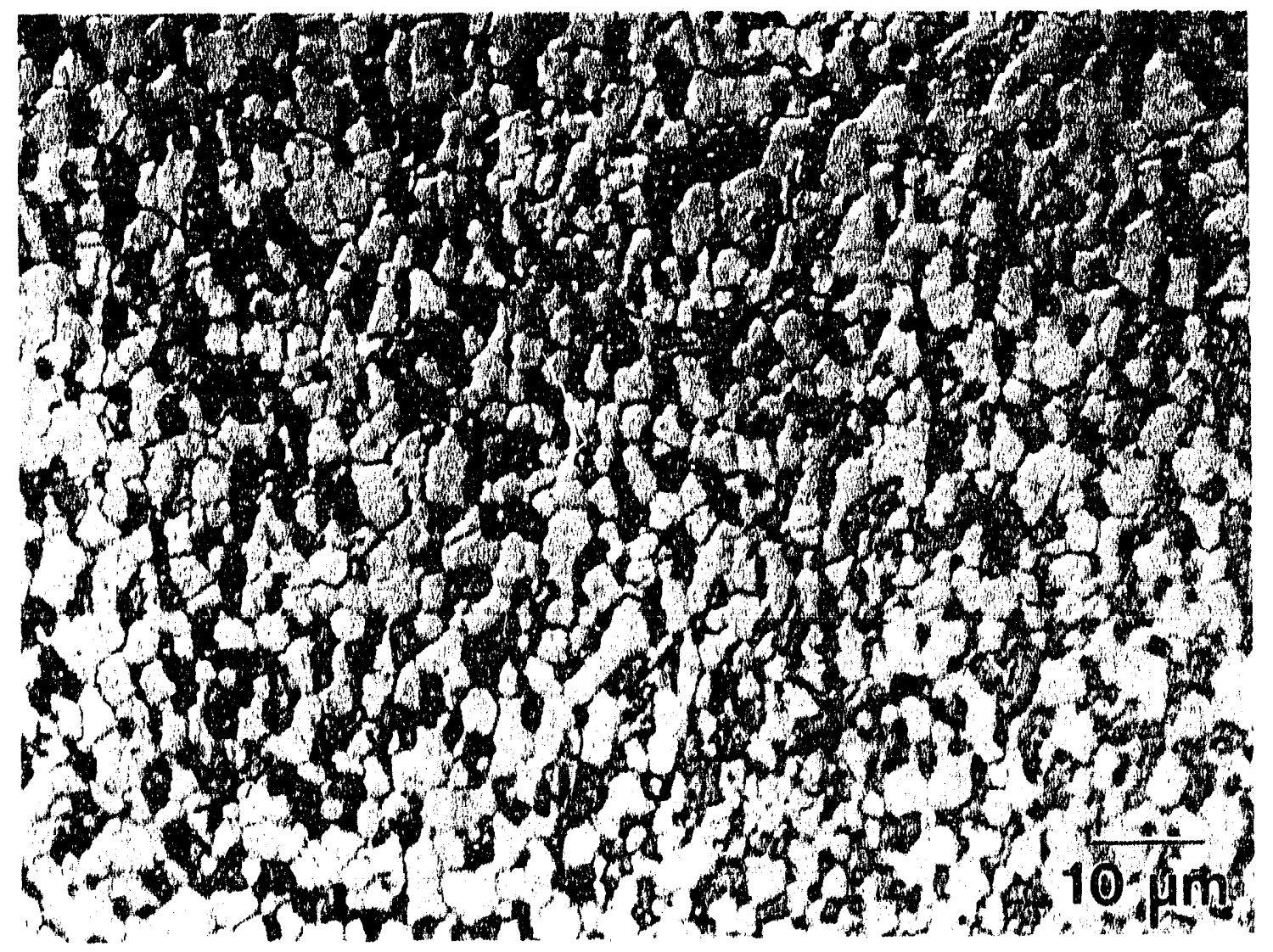

Figure 6. Optical micrograph showing a worked and annealed $60 \mathrm{Sn}-40 \mathrm{~Pb}$ microstructure. The thermomechanical treatment results in a recrystallized microstructure in which the colony features characteristic of the as-solidified structure have been completely replaced by a uniform distribution of equiaxed $\mathrm{Pb}$-rich and $\mathrm{Sn}$-rich grains. The light regions are the $\mathrm{Sn}$ rich phase, the dark regions are the Pb-rich phase. XBB885-5304 


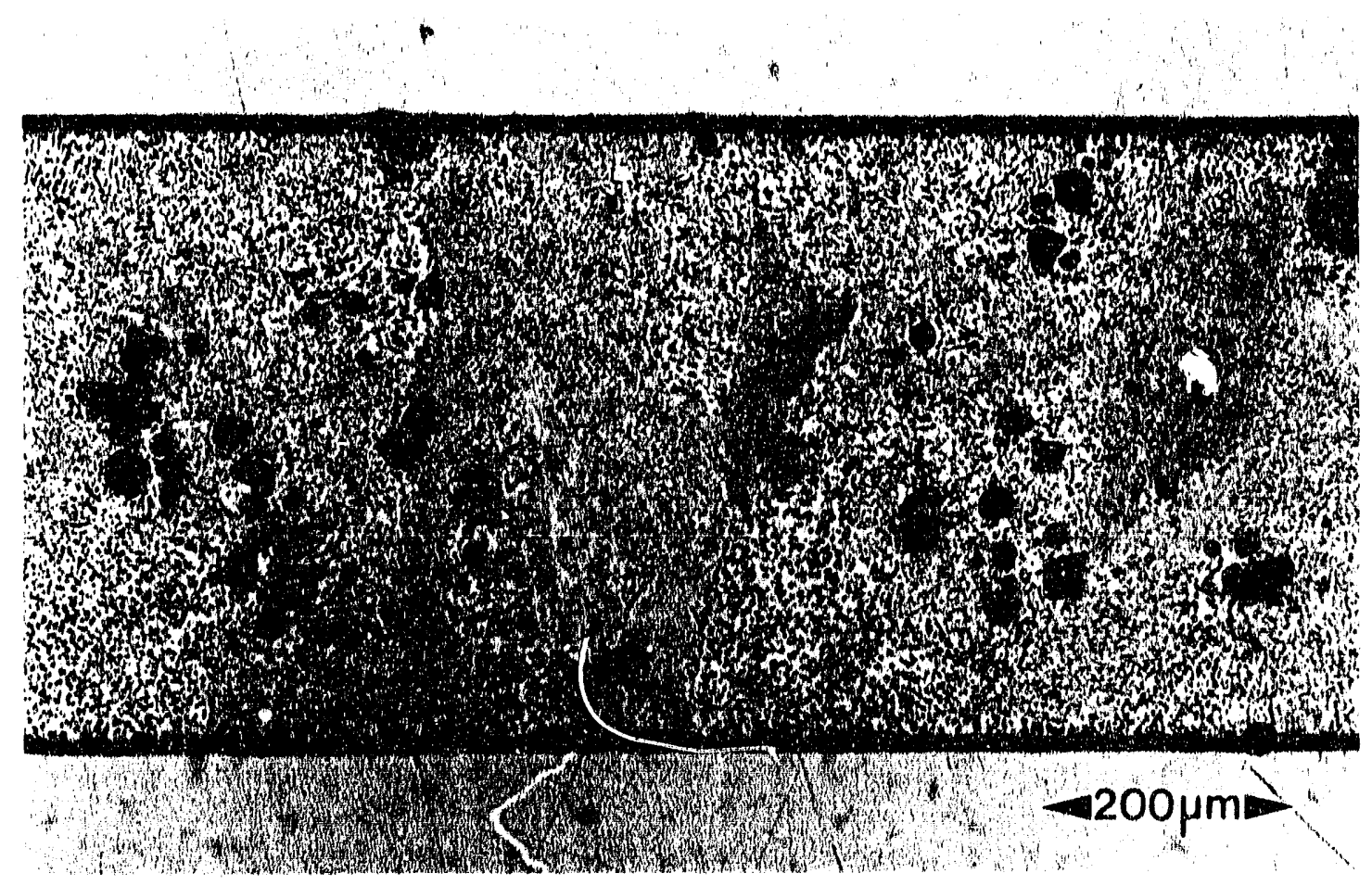

Figure 7. Optical micrograph of a typical $60 \mathrm{Sn}-40 \mathrm{~Pb}$ solder joint. The dark regions are the $\mathrm{Pb}$-rich phase. Note the phase distribution into grain like features, i.e. colonies. This solder microstructure is representative of the solder microstructures in the specimen configuration shown in Figure 11. The light regions are the $\mathrm{Sn}$-rich phase, the dark regions are the $\mathrm{Pb}$-rich phase. $\mathrm{XBB} 887-7081$ 


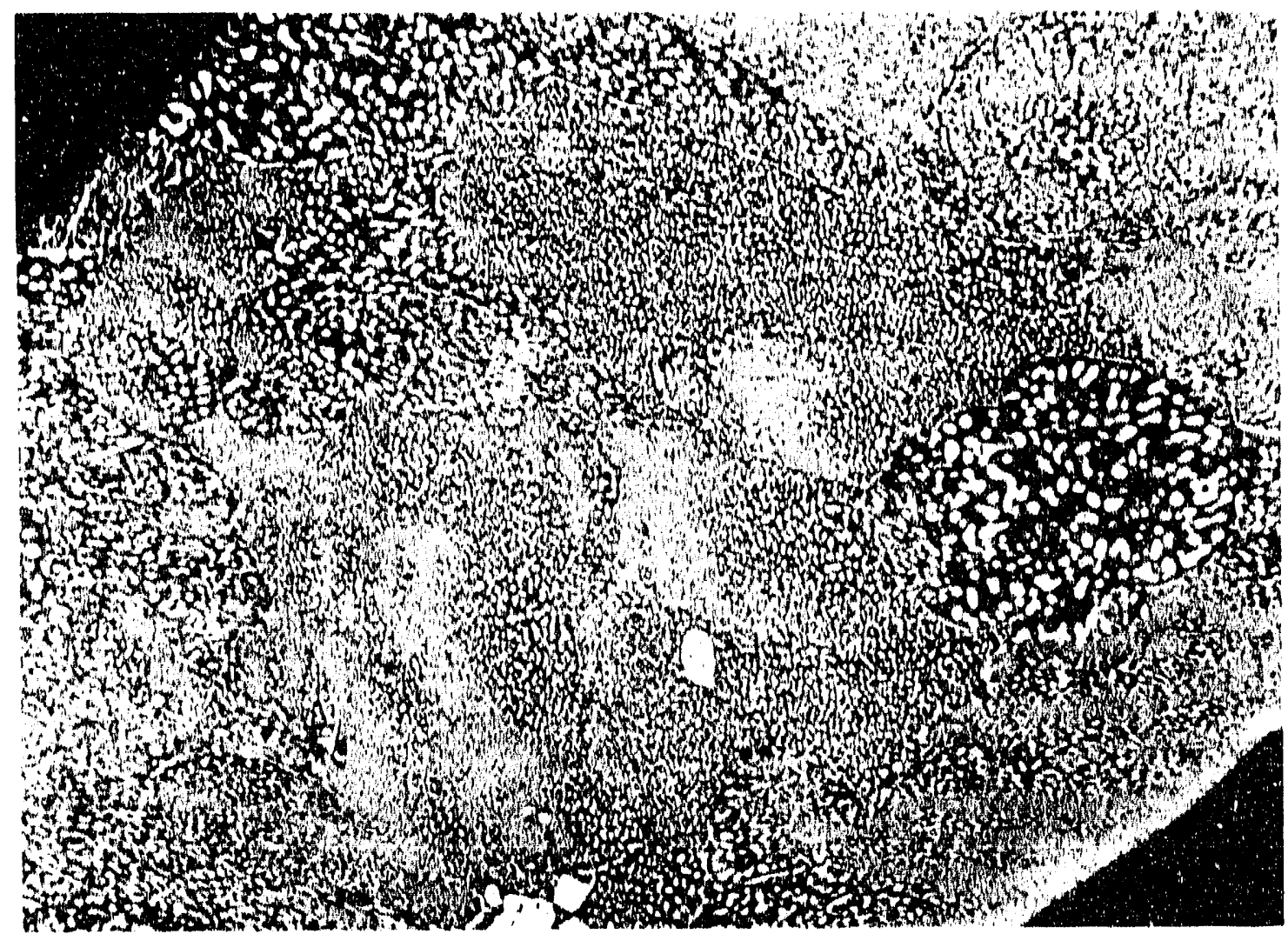

30 $\mu \mathrm{m}$

Figure 8. SEM cross section of a "real" solder joint. This particular joint was made by the wave soldering method. The microstructure contains both distinct lamellar colony features as well as regions of more degenerate character. The light regions are the $\mathrm{Pb}$-rich phase, the dark regions are the Sn-rich phase. XBB877-5535 


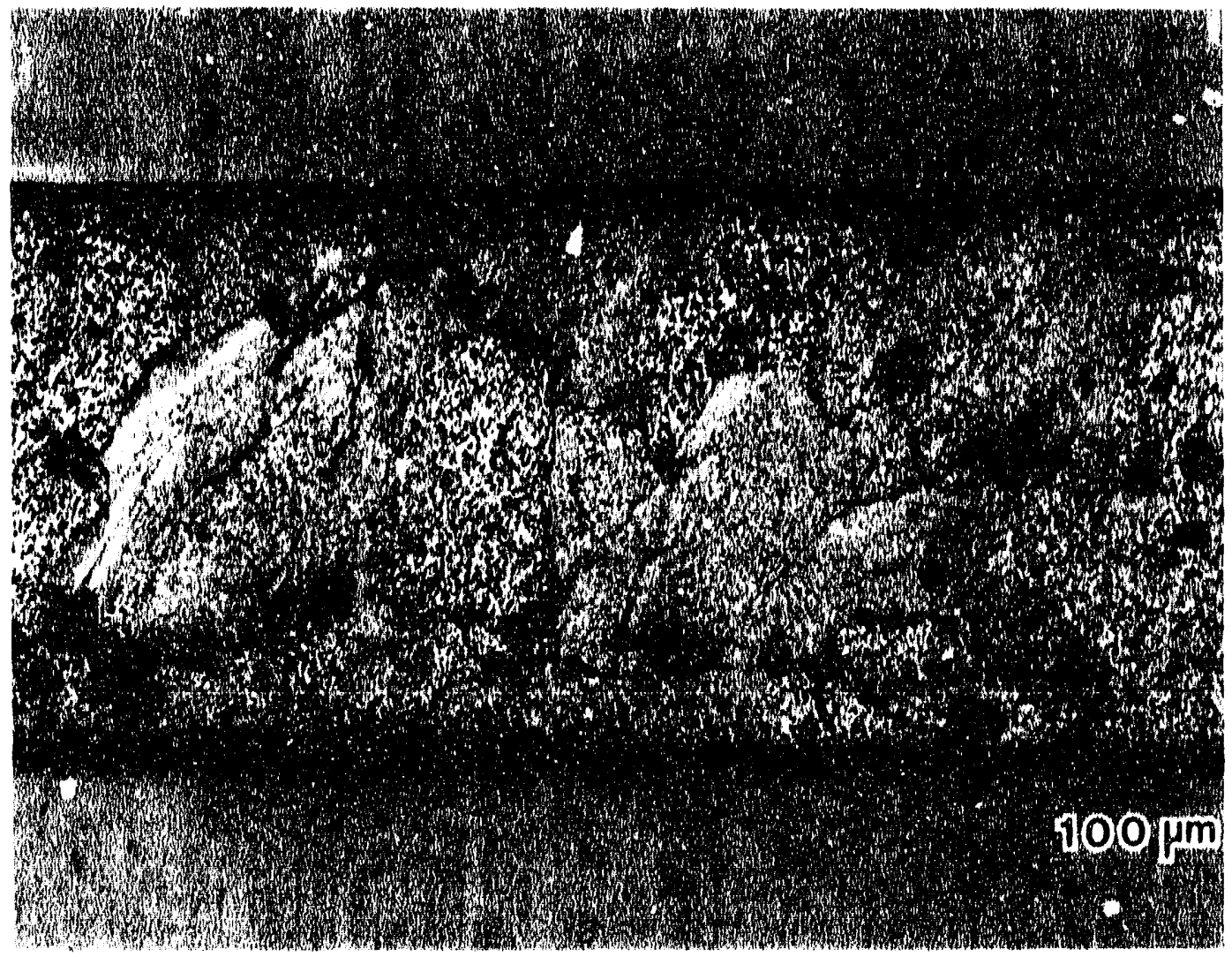

Figure 9. Optical micrograph of a $60 \mathrm{Sn}-40 \mathrm{~Pb}$ solder joint showing the surface relief that develops as the joint is deformed. The deformation pattern shows that the response of the solder microstructure is highly inhomogeneous; deformation occurs predominantly at the colony boundaries where the strengthening mechanisms that characterize the interior of a eutectic colony are lacking. The light regions are the $\mathrm{Sn}$-rich phase, the dark regions are the $\mathrm{Pb}$-rich phase. XBB902-1232 


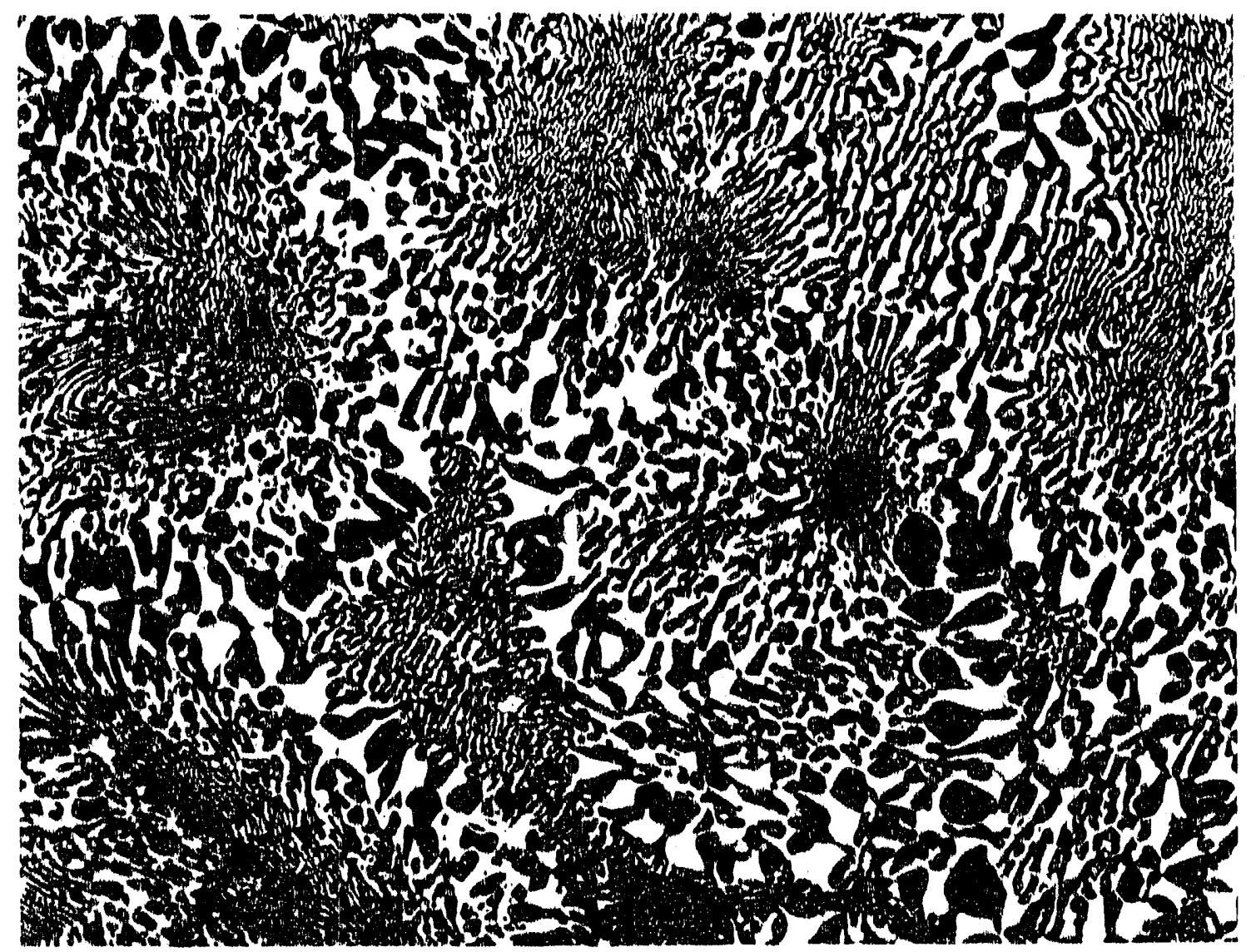

$25 \mu \mathrm{m}$

Figure 10. Optical micrograph showing microhardness traces across a multi-colony eutectic $\mathrm{Pb}-\mathrm{Sn}$ microstructure. The hardness values illustrate the difference in mechanical response between the fine lamellar phase arrangement inside a colony, relatively hard material (17 Vicker's microhardness number), and the degenerate coarsened features at the colony boundary, relatively soft material (11 Vicker's microhardness number). The light regions are the $\mathrm{Sn}$-rich phase, the dark regions are the $\mathrm{Pb}$-rich phase. $\mathrm{XBB} 902-1451$ 


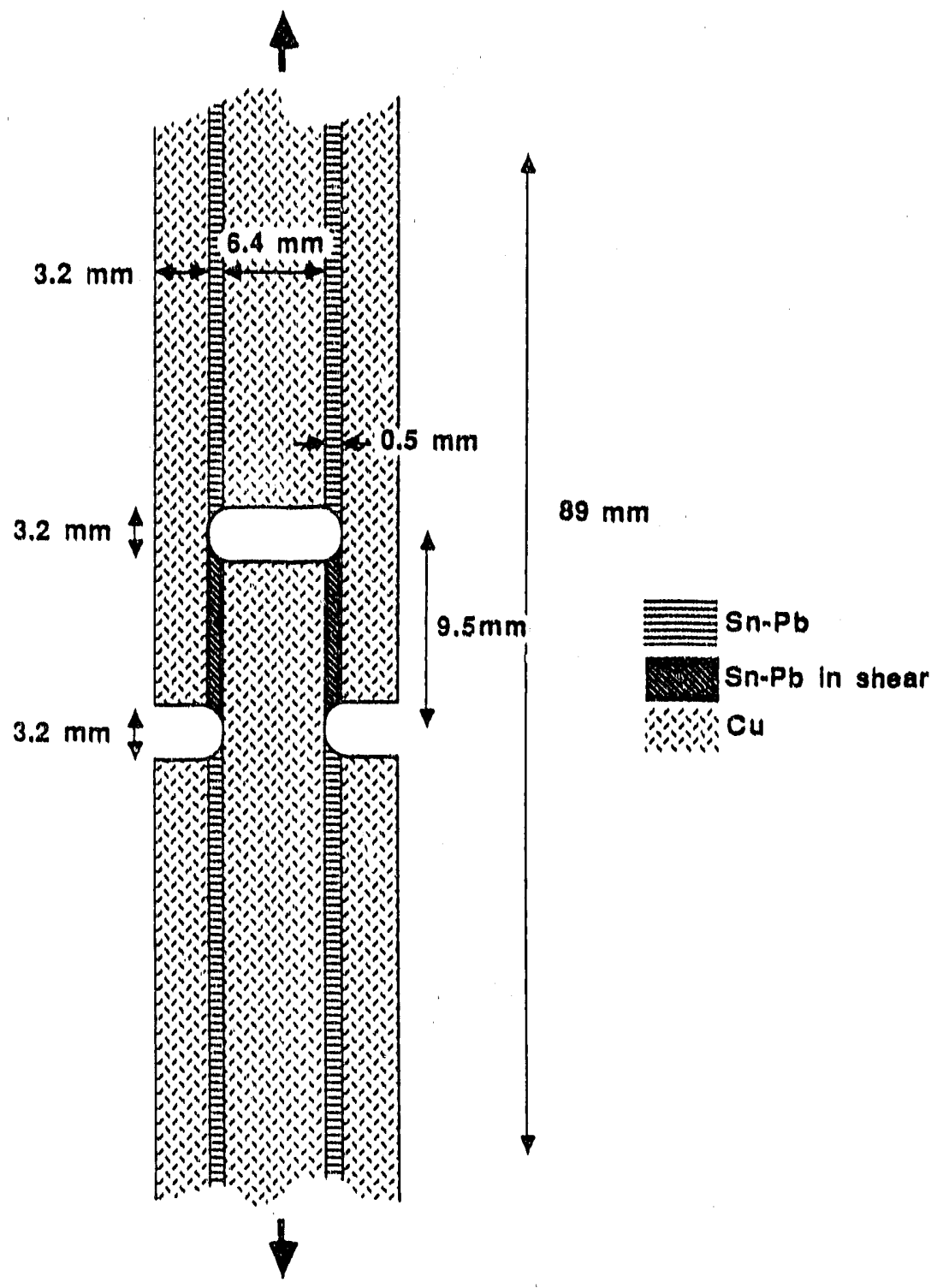

Figure 11. The specimen configuration used for shear strength, and creep testing. The specimen is a multi-layer copper/solder sandwich. On axial loading, the two solder joints, shaded regions in figure, are loaded in nearly simple shear. Dimensions are in mm. The specimen thickness is $1.5 \mathrm{~mm}$. 


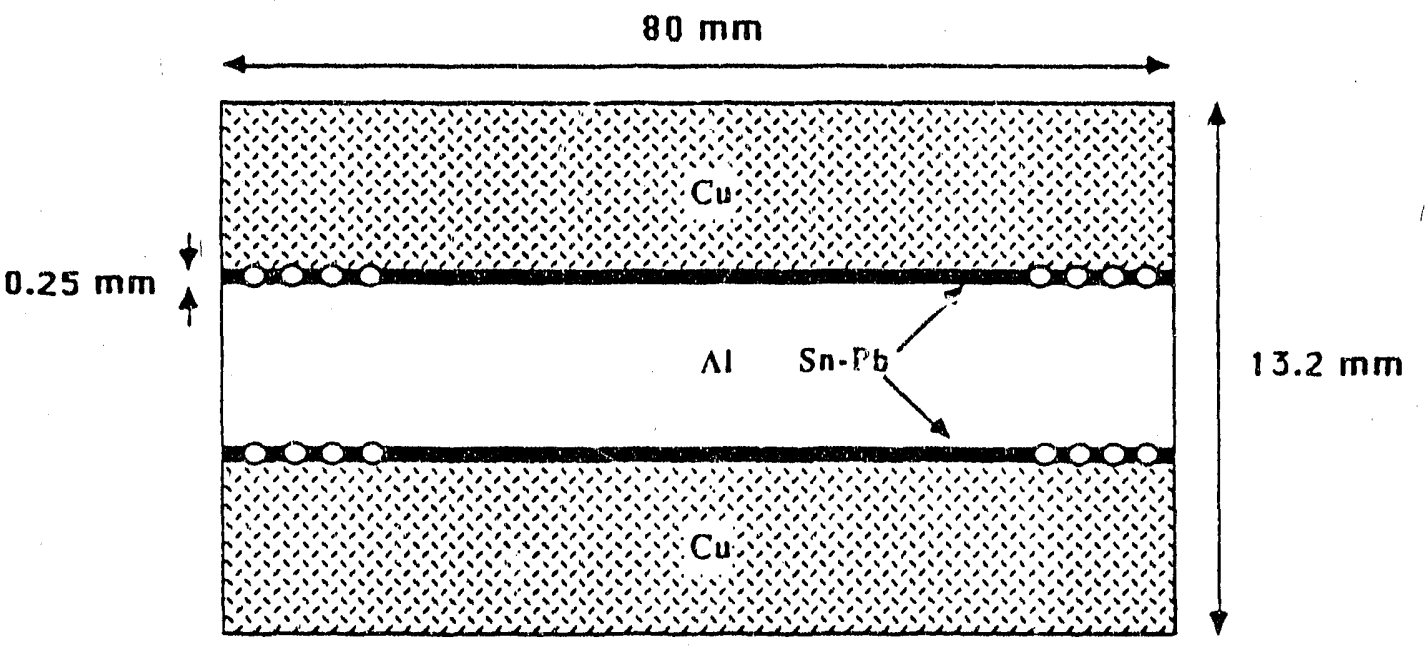

Figure 12. Specimen used for thermal fatigue experiments. The dark central regions are the solder joints. The mismatched thermal expansion characteristics of the constraining copper and aluminium strain the solder joints in shear with each temperature excursion. Since the strain magnitude varies linearly from the center of the specimen to a maximum strain at the edges, the holes along the leng git of uhe solder joints serve to isolate individual solder regions at a particular strain level. $(80 \mathrm{~mm}=21$ and $0.25=w$ in equation (1).) 


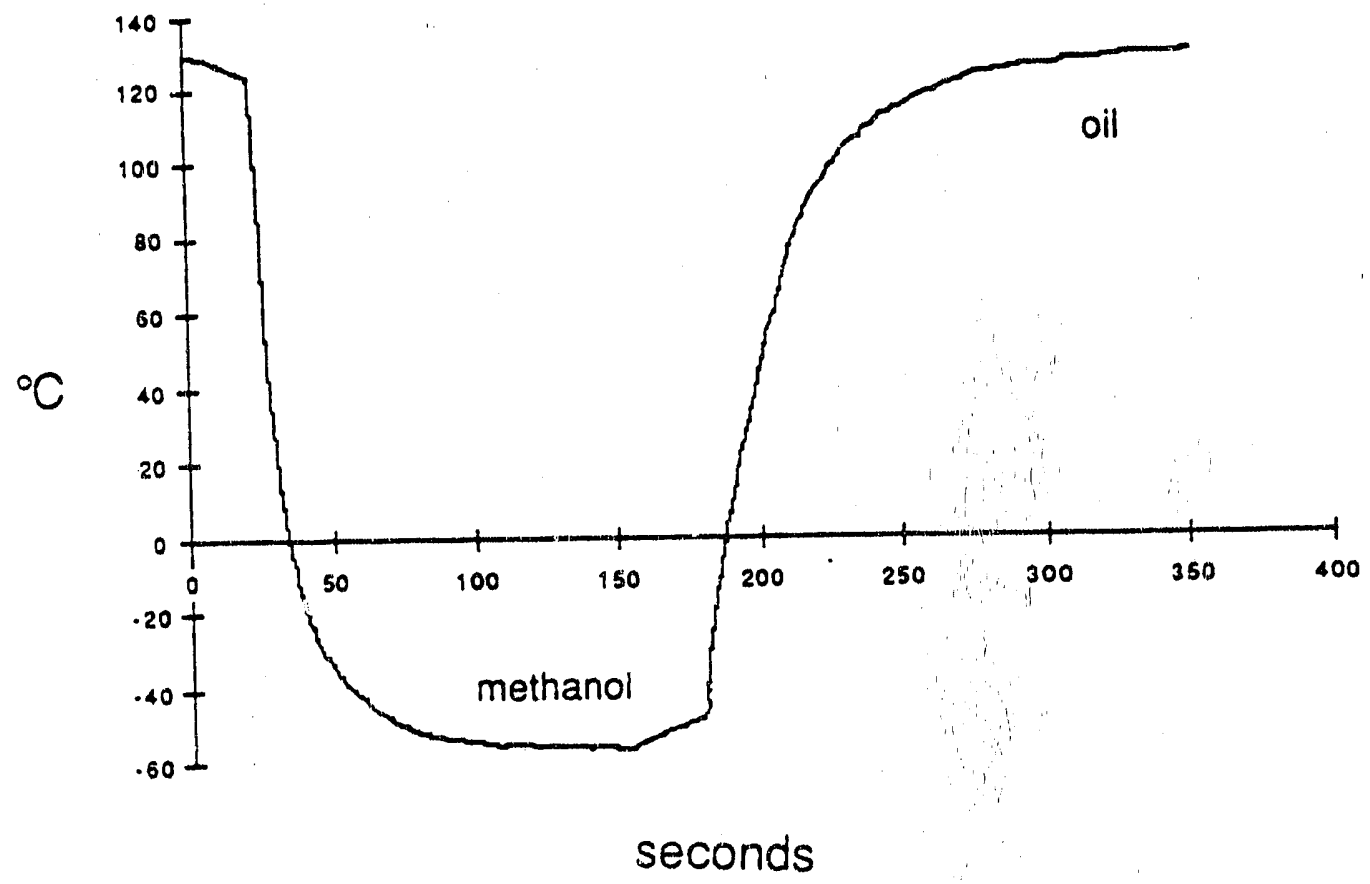

Figure 13. Time/temperature profile of the thermal fatigue specimen for a $-55^{\circ} \mathrm{C}$ to $125^{\circ} \mathrm{C}$ temperature cycle. The data are the output from a thermocouple attached directly to the specimen. 

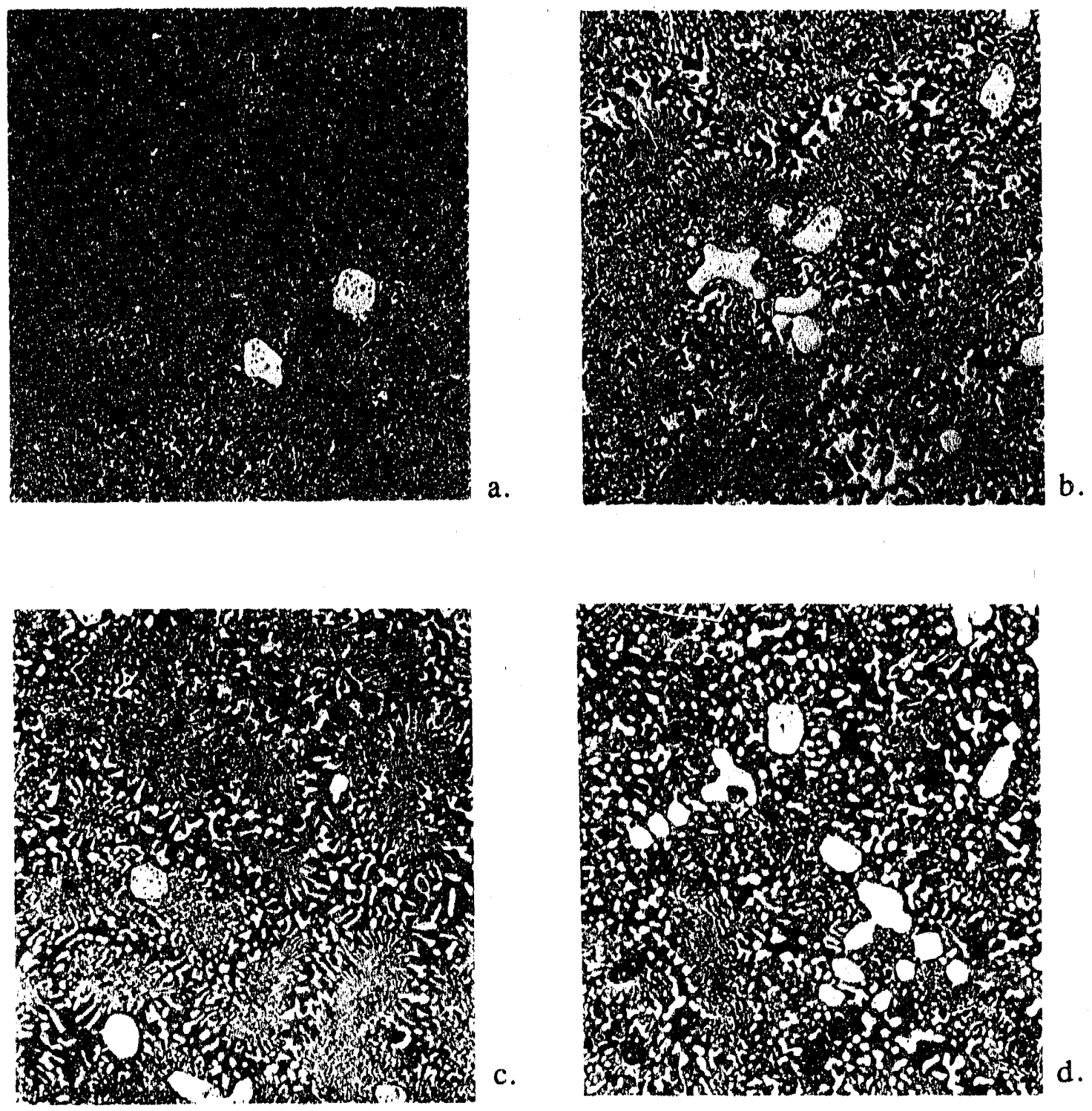

$75 \mu \mathrm{m}$

Figure 14. Optical micrographs of several ternary alloys: a. $58 \mathrm{Sn}-40 \mathrm{~Pb}-2 \mathrm{Bi}$, b. $58 \mathrm{Sn}$ $40 \mathrm{~Pb}-2 \mathrm{Sb}$, c. $58 \mathrm{Sn}-40 \mathrm{~Pb}-2 \mathrm{In}, 58 \mathrm{Sn}-40 \mathrm{~Pb}-2 \mathrm{Cd}$. All microstructures are the result of identical processing histories, hence, the microstructural changes are due to compositional changes only. Note the appearance of diffuse colony boundaries and the associated increase in the amount of degenerate material with the In and $\mathrm{Cd}$ additions. The light regions are the $\mathrm{Sn}$-rich phase, the dark regions are the $\mathrm{Pb}$-rich phase.

a.b XBB 898-6549; c.d XBB 898-6542 


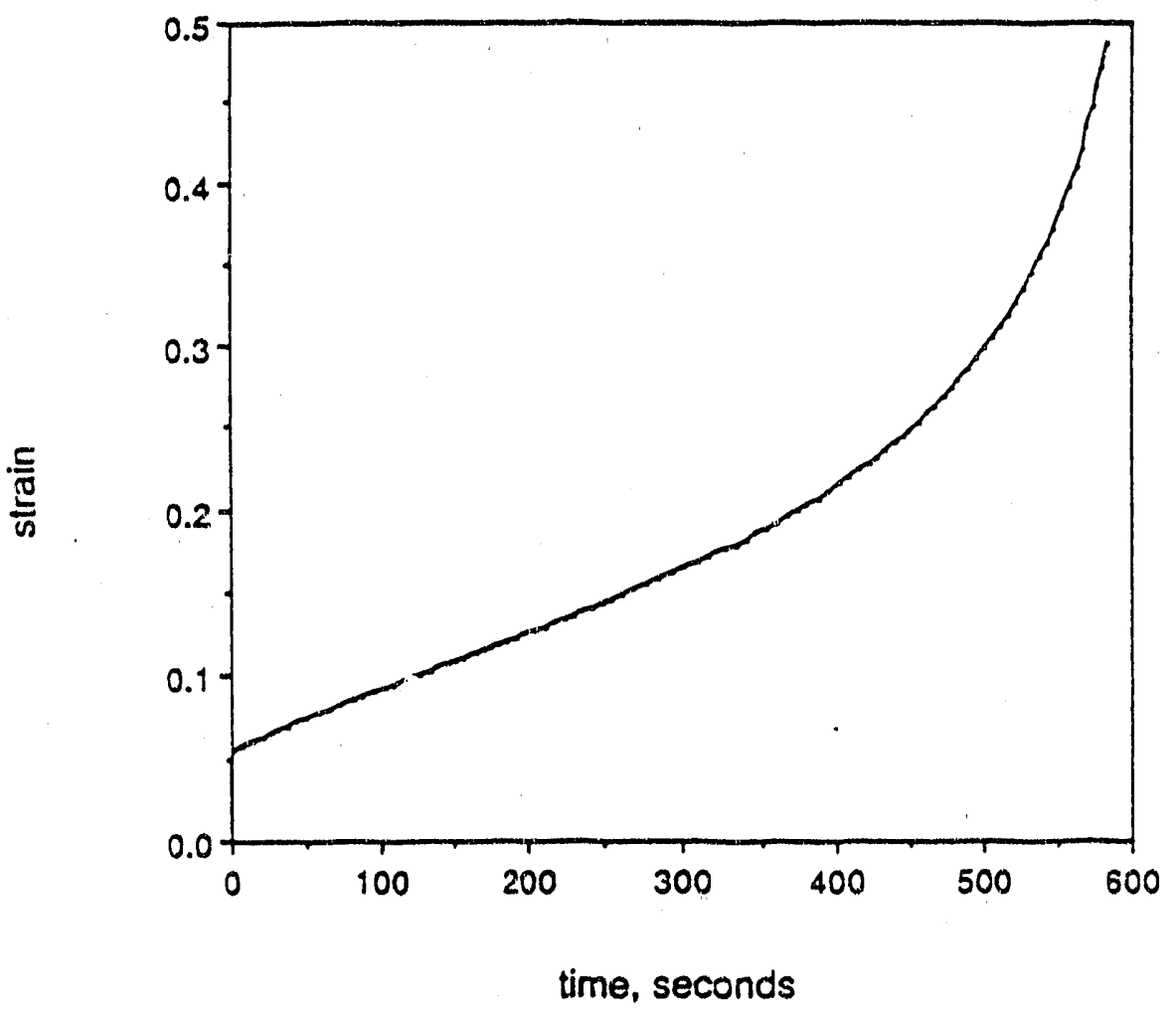

Figure 15. A typical creep curve. This curve represents creep of the $58 \mathrm{Sn}-40 \mathrm{~Pb}-2 \mathrm{Sb}$ alloy at $125^{\circ} \mathrm{C}$ under an $8.8 \mathrm{MPa}(1280 \mathrm{psi})$ stress. 


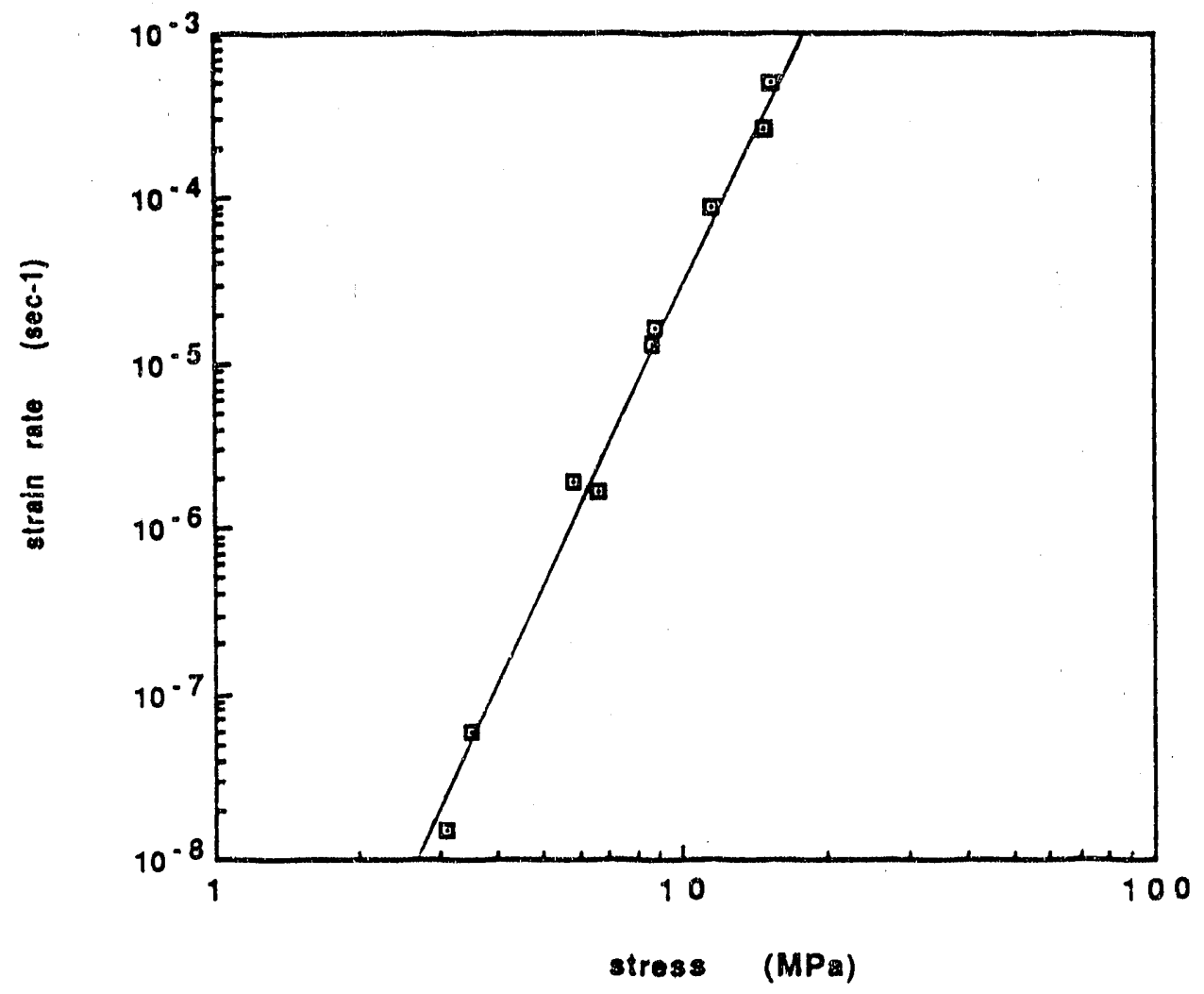

Figure 16. A plot of steady-state strain rate vs. stress, at constant temperature $\left(75^{\circ} \mathrm{C}\right)$, for the eutectic $\mathrm{Pb}-\mathrm{Sn}(61.9 \mathrm{Sn}-38.1 \mathrm{~Pb})$ alloy. The slope of the line is equal to 6.3 , indicating conventional plasticity. 


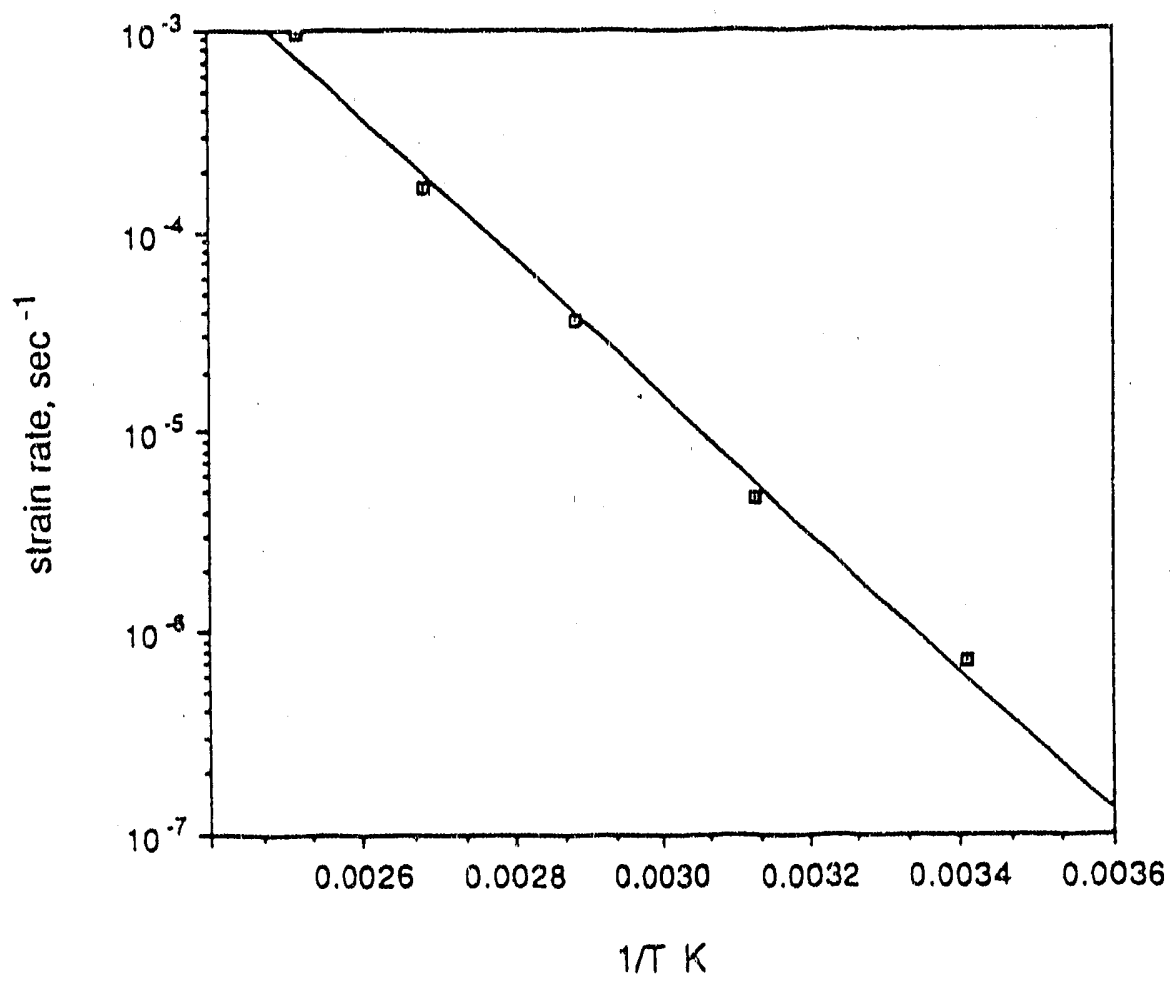

Figure 17. A plot of steady-state strain rate vs inverse temperature, at a constant stress $(8.8 \mathrm{MPa} / 1280 \mathrm{psi})$ for the $58 \mathrm{Sn}-40 \mathrm{~Pb}-2 \mathrm{Cd}$ alloy. The activation energy is computed form the slope of the line (see Table I). 


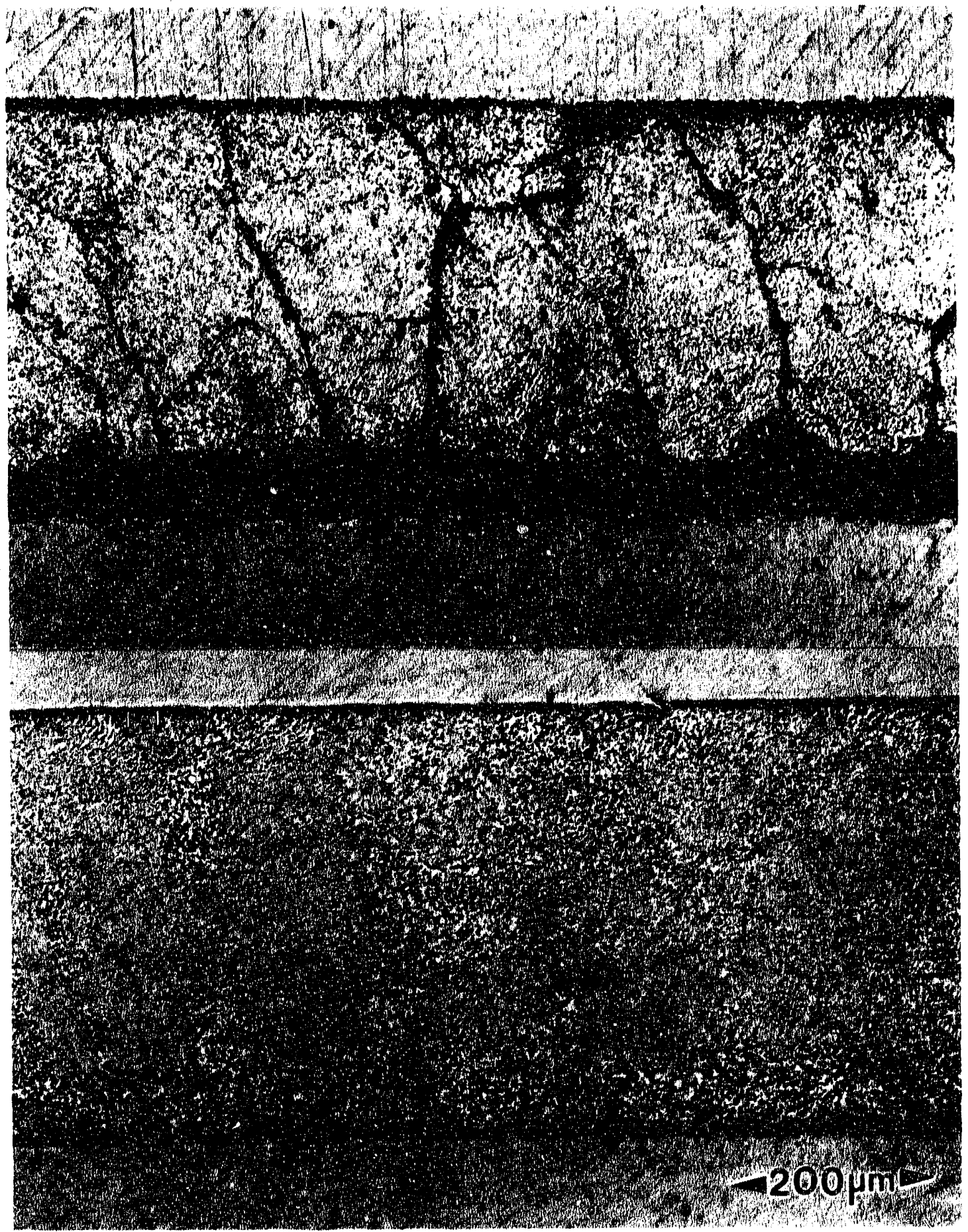

Figure 18. Optical micrograph of a polished solder joint deformed in shear. (top) The surface relief that develops with deformation. The deformation is localized to a thin band near the $\mathrm{Cu} /$ solder interface and along colony boundaries elsewhere in the joint. (bottom) The same specimen as in (top), but polished to remove the surface relief. There is an exact correspondence between the location of the major deformation band and a band of recrystallized and coarsened microstructure. The deformation elsewhere in the joint corresponds to the irregular material at the colony boundaries. The light regions are the $\mathrm{Sn}$ rich phase, the darik regions are the $\mathrm{Pb}$-rich phase. $\mathrm{XBB} 887-7084$ 


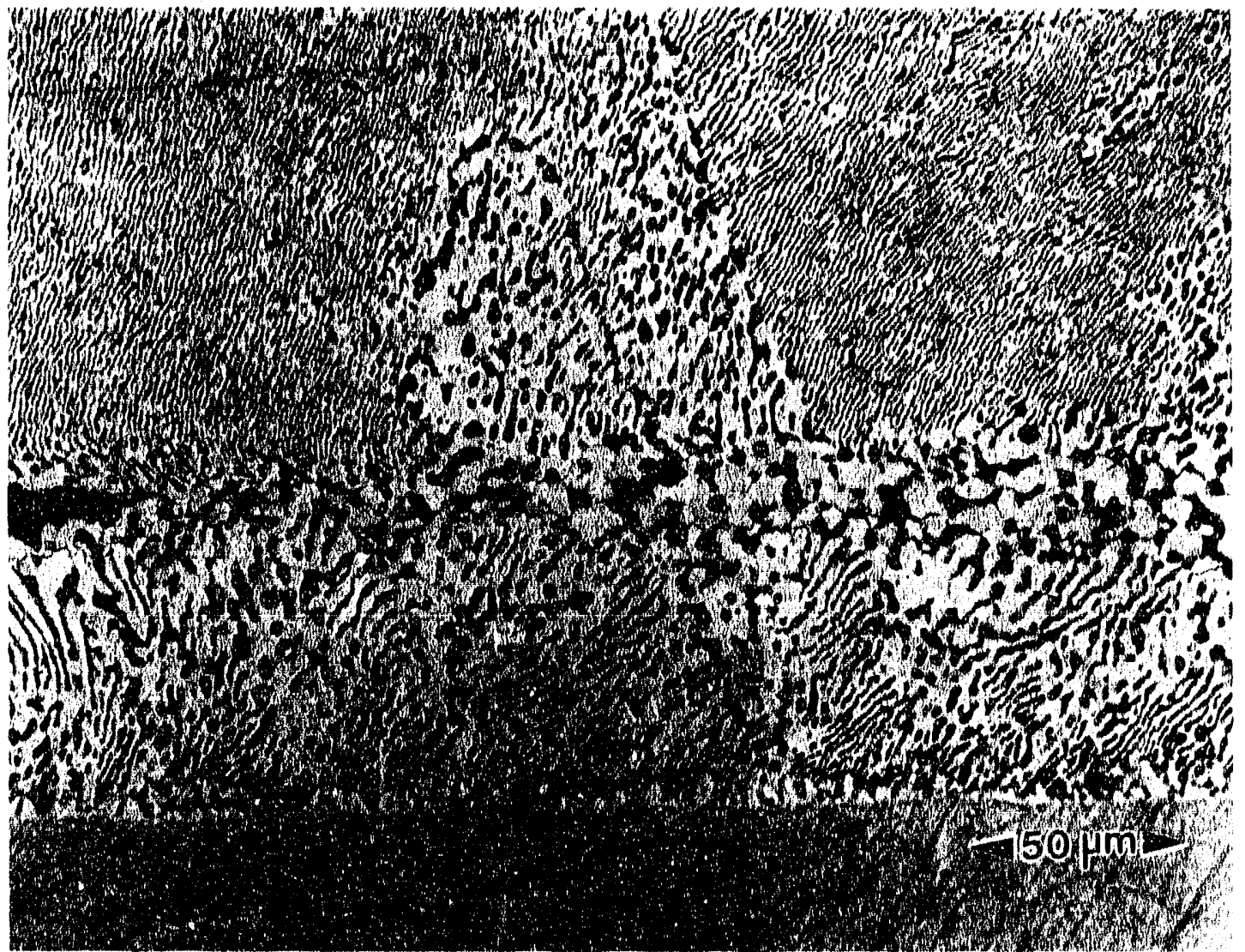

Figure 19. Detail of the coarsened band seen in Figure 18 showing its definition and the presence of equiaxed $\mathrm{Pb}$ - and $\mathrm{Sn}$ - rich phase grains apparently formed by recrystallization (optical). The light regions are the $\mathrm{Sn}$-rich phase, the dark regions are the $\mathrm{Pb}$-rich phase. XBB-887-7083 
61

1

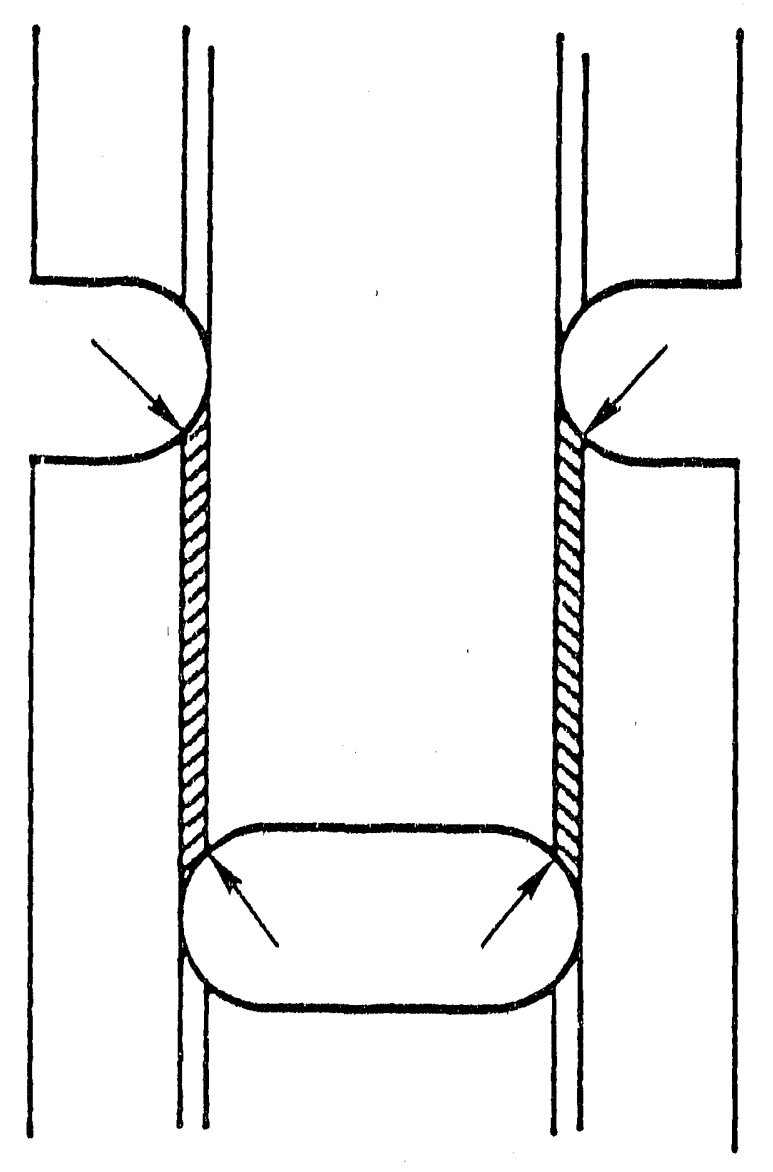

Figure 20. Schematic of the double shear specimen (Figure 11) showing the principal stress concentration in this joint geometry. 


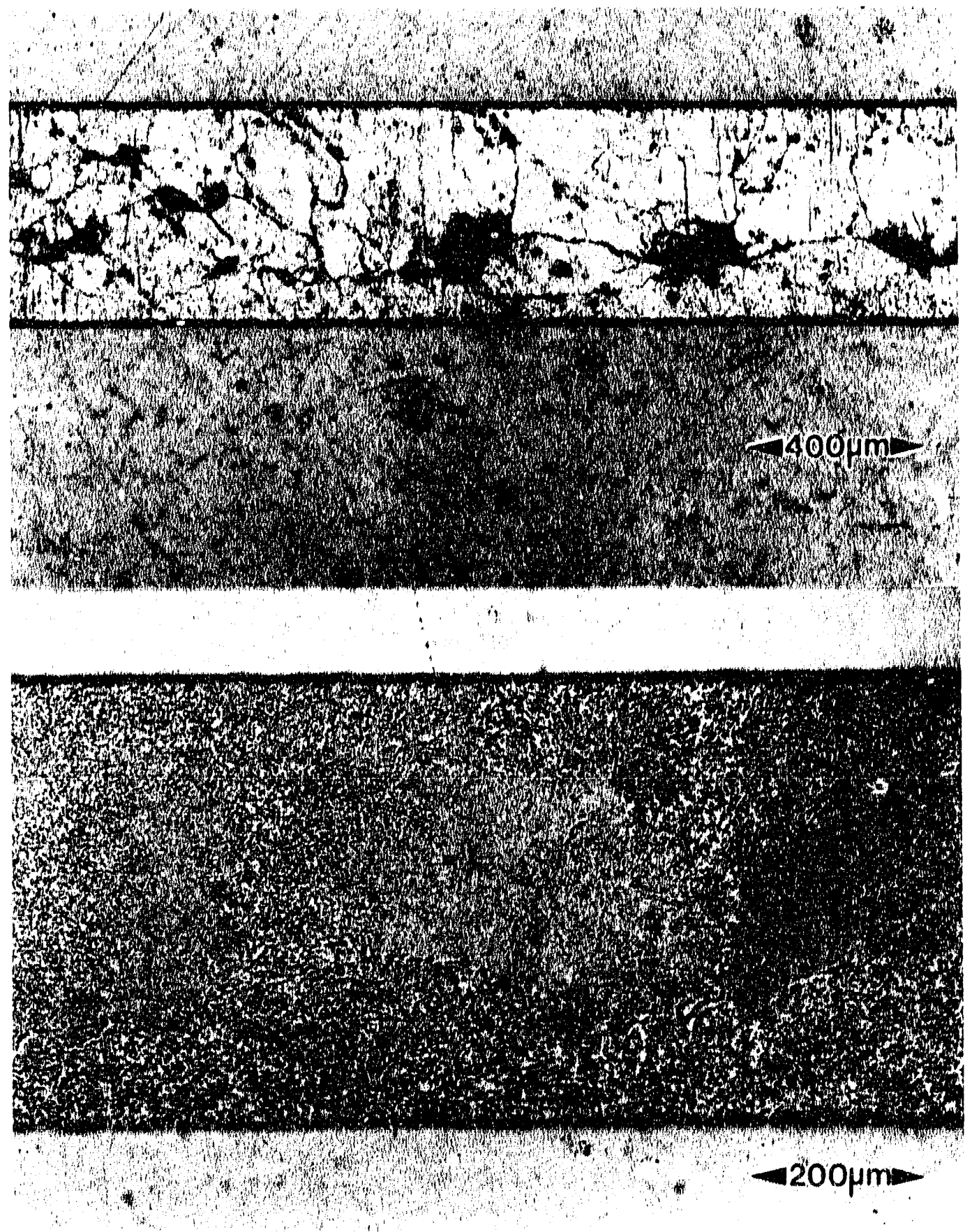

Figure 21. Optical micrograph of a polished solder joint deformed slowly in shear, $10^{-8} \mathrm{sec}^{-1}$. (top) The surface relief that develops with deformation. (bottom) The same specimen as in (top), but polished to remove the surface relief. The deformed regions correspond exactly to colony boundaries. The light regions are the Sn-rich phase, the dark regions are the $\mathrm{Pb}$-rich phase. $\mathrm{XBB} 887-7082$ 

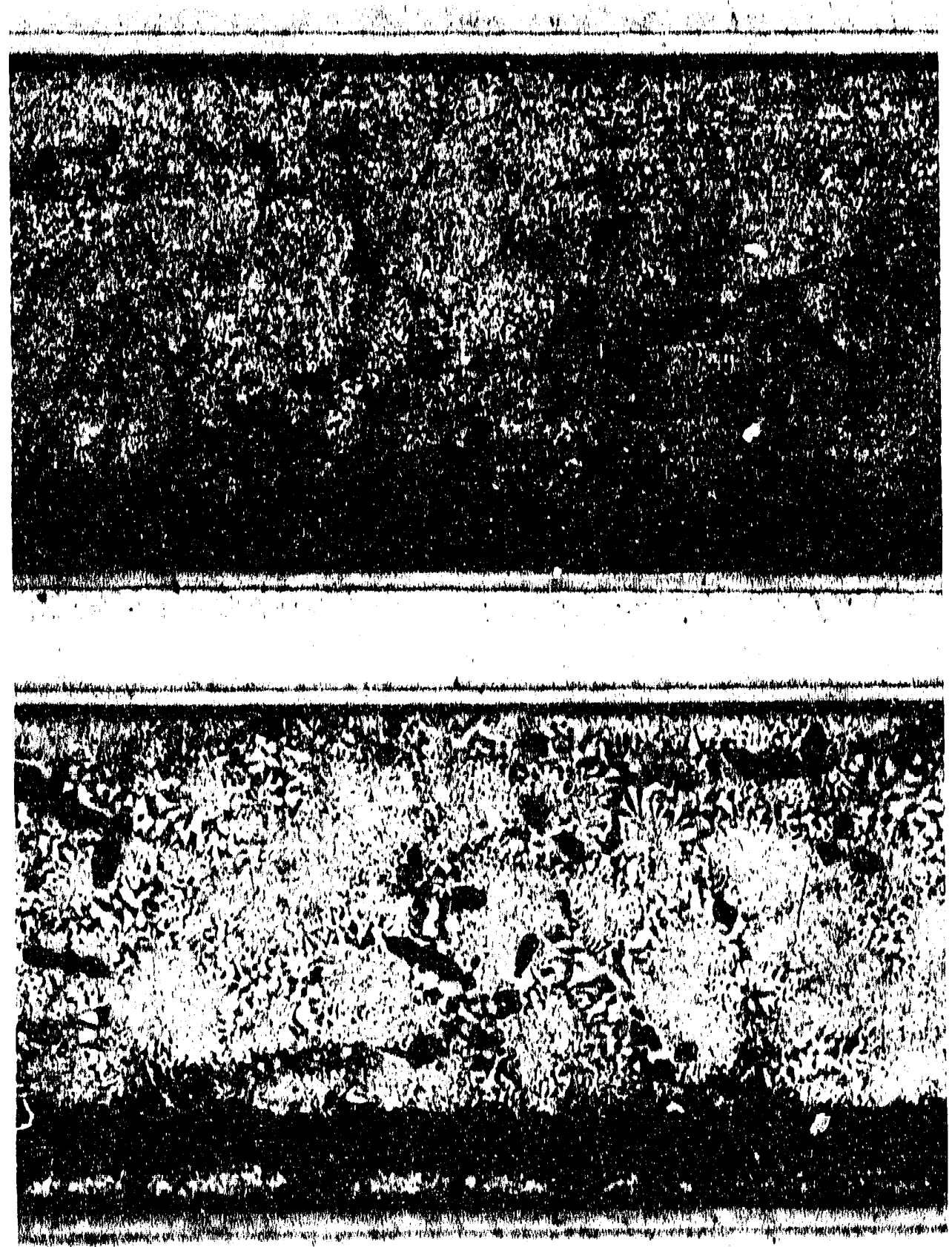

$50 \mu \mathrm{m}$

Figure 22. The surface relief that is observed after creep deformation of the (top) Sb- and (bottom) Bi- alloyed solders. The deformation patterns are similar to those observed for the simple binary alloy: deformation is largely localized to a thin band parallel to the copper/solder interface. top, XBB 898-6553; boltom, XBB 898-6.555 

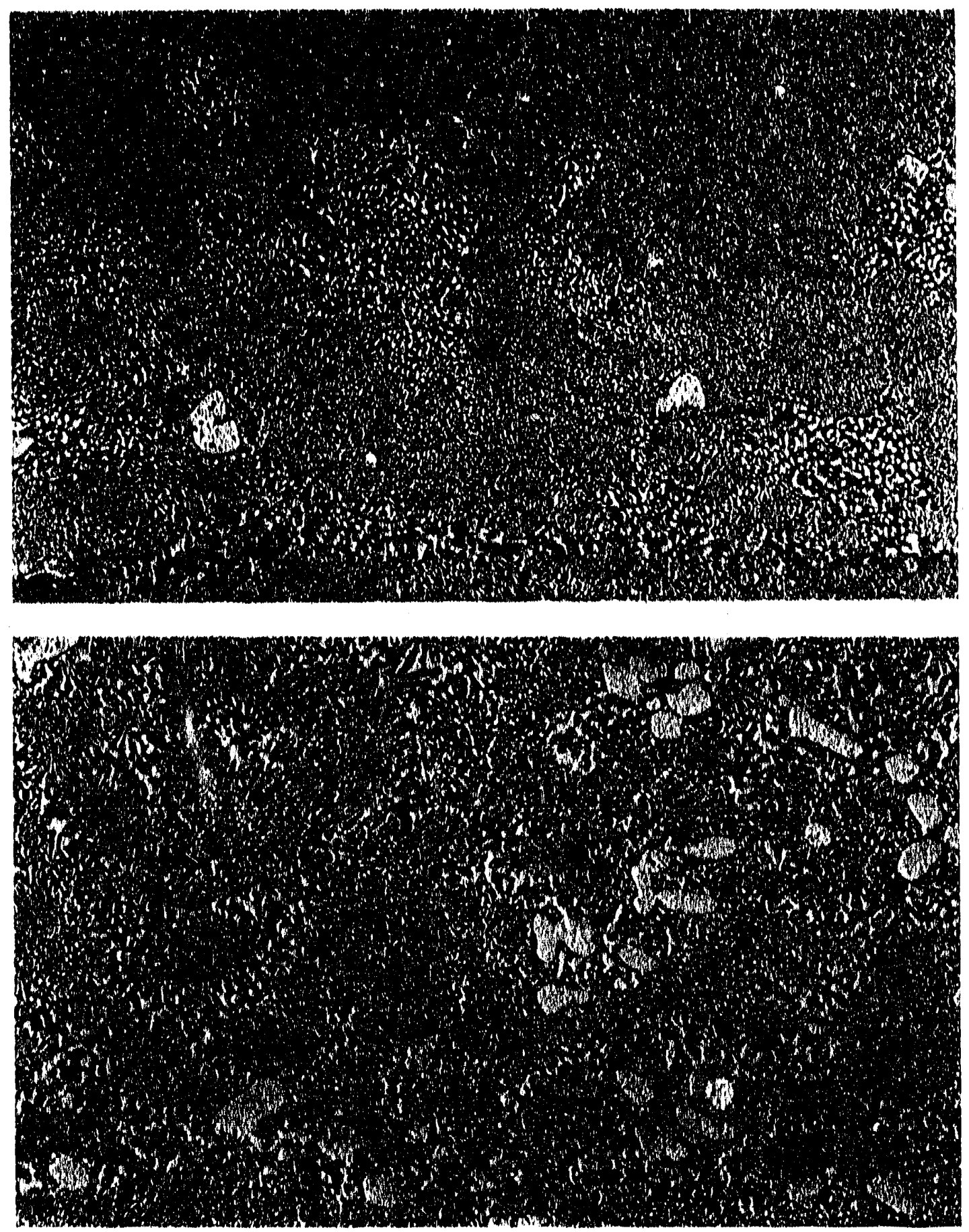

$75 \mu \mathrm{m}$

Figure 23. The polished microstructures of the deformed (top) Sb-alloyed and (bottom) Bi-alloyed specimens seen in Figure 22. As was the case with the binary solders, the deformation is associated with microstructural changes: a coarsened band is clearly visible running parallel to the copper/solder interface. top, XBB 898-6556; bottom, XBB 898-65.52 

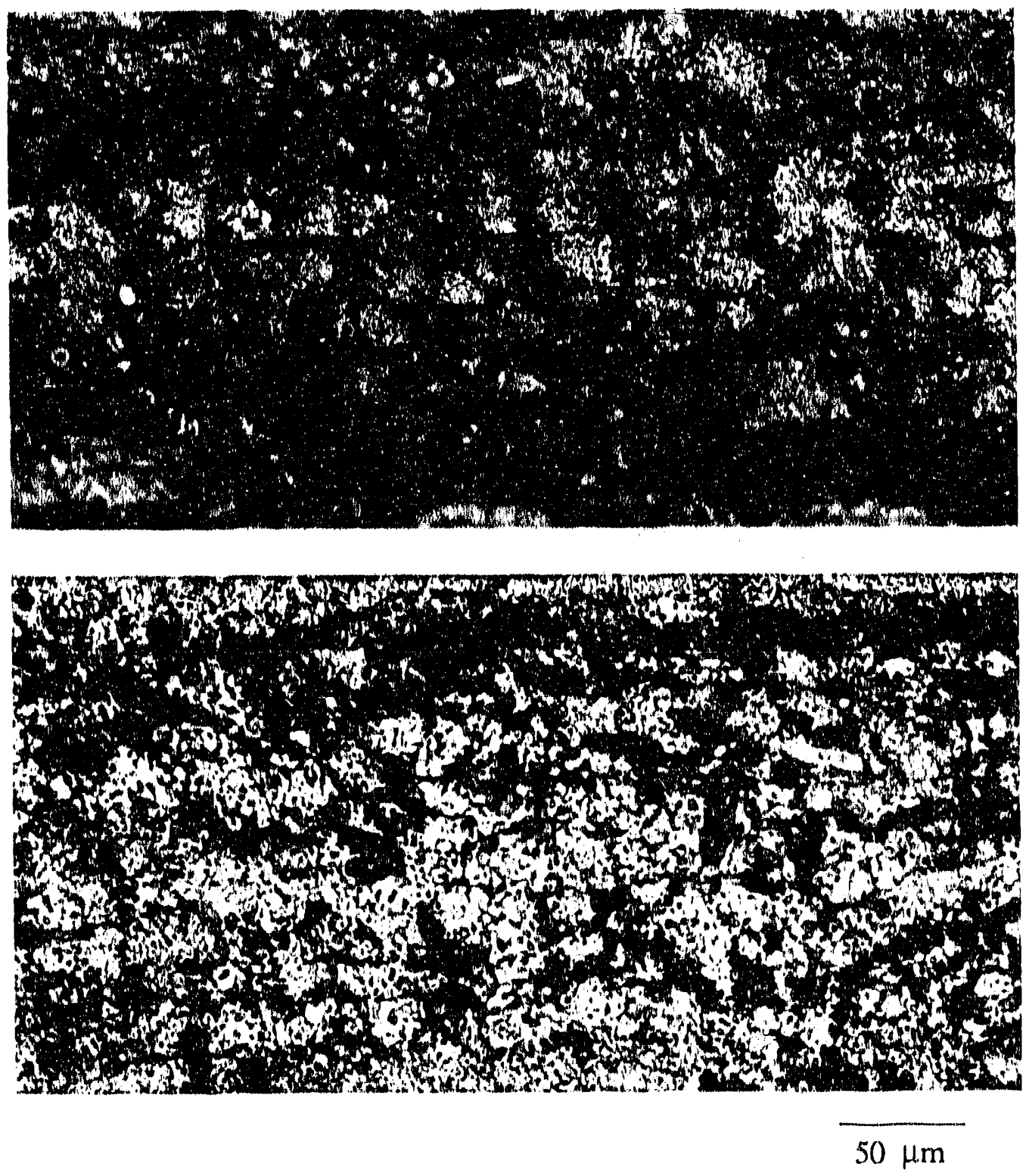

Figure 24. The surface relief that is observed after creep deformation of the (top) In- and (bottom) Cd- alloyed solders. The deformation patterns reveal significantly more uniform deformation throughout the entire joint than was observed for the simple binary alloy. (Optical micrographs: the light regions are the $\mathrm{Sn}$-rich phase, the dark regions are the $\mathrm{Pb}$ rich phase.) top, XBB898-6550; bottom, XBB898-6541 

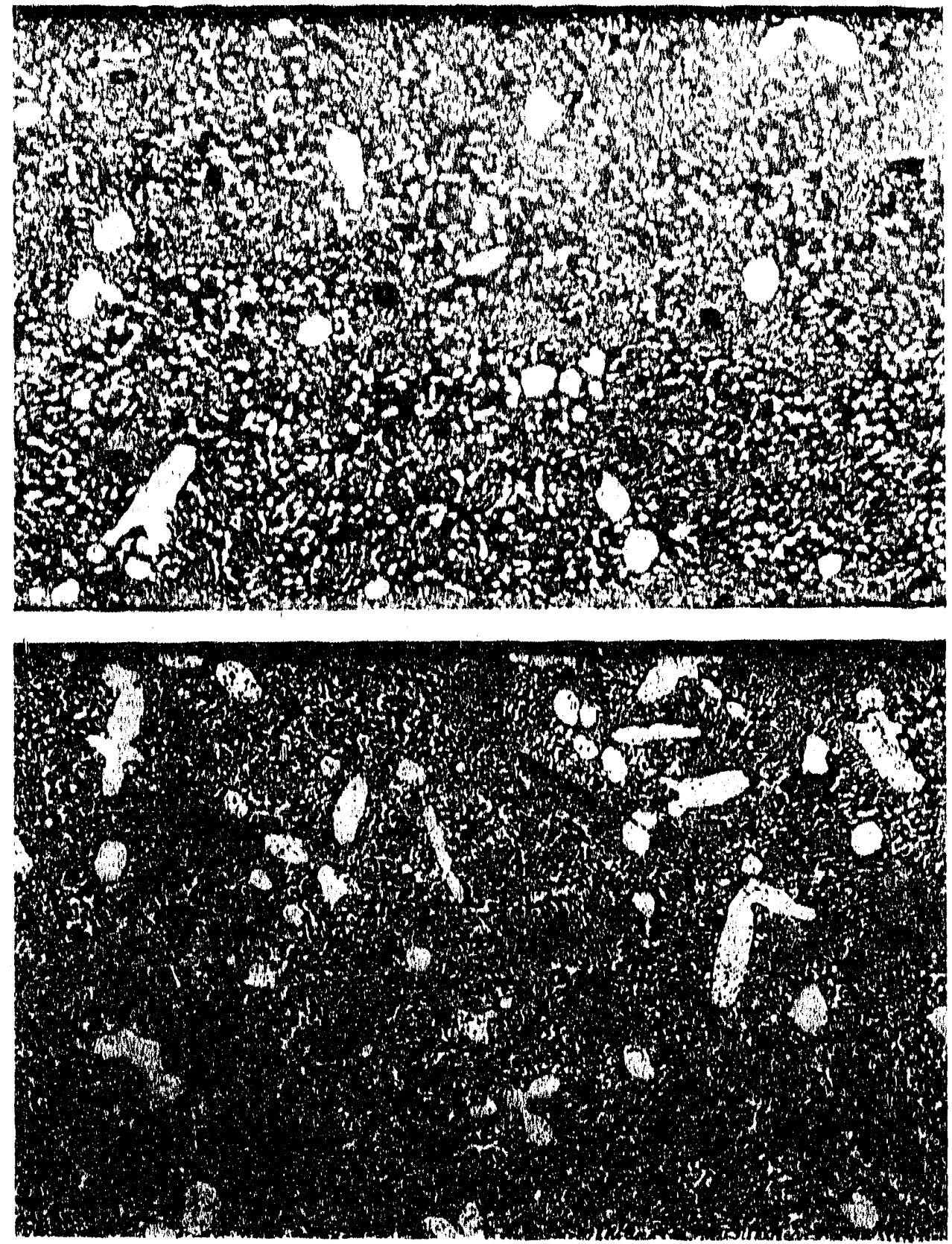

$75 \mu \mathrm{m}$

Figure 25. The polished microstructures of the deformed (top) Cd-alloyed and (bottom) Inalloyed specimens seen in Figure 25. The deformation is not associated with microstructural changes, as was the case with the binary alloys. (SEM micrographs: the light regions are the $\mathrm{Pb}$-rich phase, the dark regions are the $\mathrm{Sn}$-rich phase.) top, XBB 898-6551; bottom, XBB 898-6554 

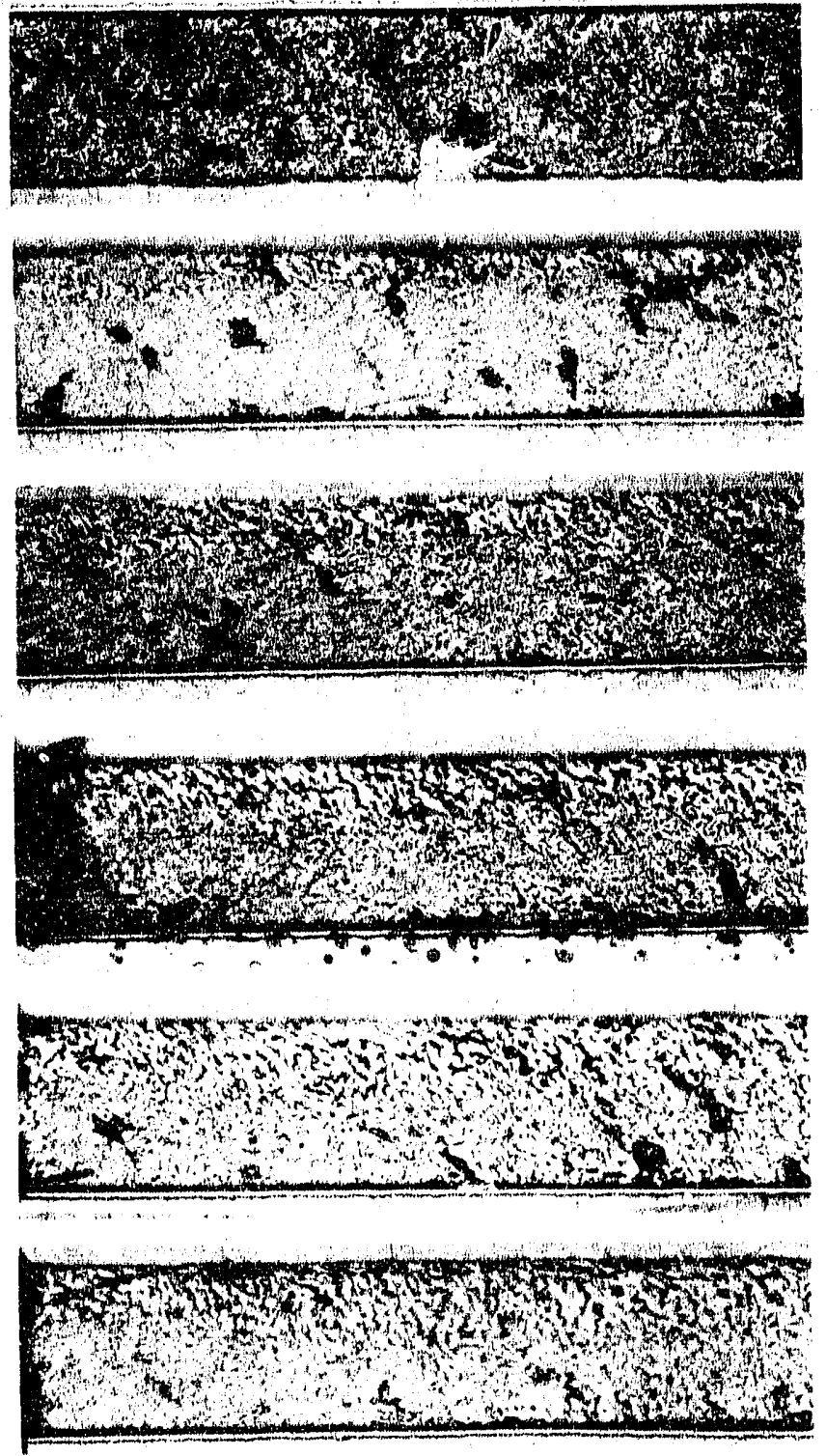

$200 \mu \mathrm{m}$

Figure 26. A series of optical micrographs showing the microstructural evolution of a $60 \mathrm{Sn}-40 \mathrm{~Pb}$ solder joint as it is cycled between $-55^{\circ} \mathrm{C}$ and $125^{\circ} \mathrm{C}$. Relatively early on in the cycling, a band of coarsened microstructure appears near the substrate/solder interface. This band becomes more pronounced with increased thermal cycles, eventually cracks initiate within this coarse microstructure causing the joint's failure. The top image is the initial microstructure; subsequent images are taken from the same place in the joint at 333 thermal cycle increments. The last image, with crack, represents 1700 cycles. These joints correspond to a nominal shear sirain of $23 \%$. The joini widtin is 0.3 minn ( 0.010 inches). XBB898-6544 

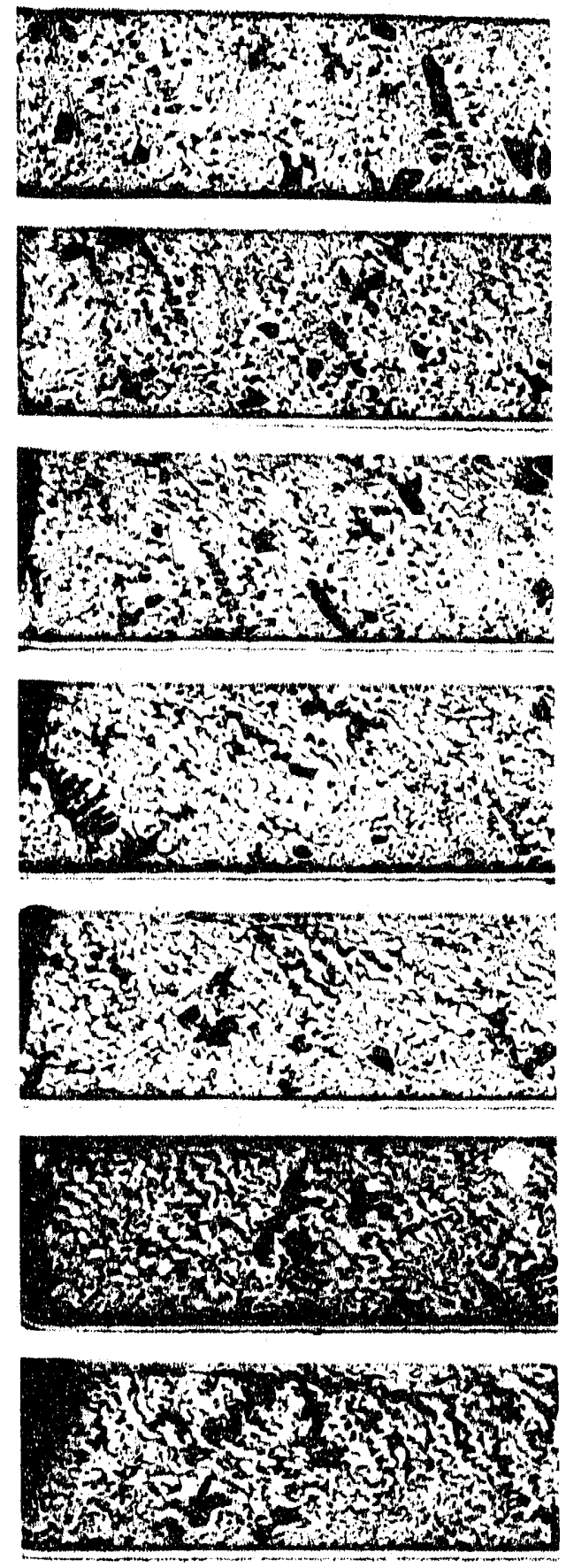

$175 \mu \mathrm{m}$

Figure 27. A series of optical micrographs showing the microstructural evolution as a $58 \mathrm{Sn}-40 \mathrm{~Pb}-2 \mathrm{Cd}$ solder joint is cycled between $-55^{\circ} \mathrm{C}$ and $125^{\circ} \mathrm{C}$. Coarsening of the solder is already apparent with 670 thermal cycles. Coarsening initiates at the coarsened degenerate material at the colony boundaries and slowly consumes the entire solder microstructure. Cracking occurs once the joint has coarsened, and is visible in the bottom image. The top image is the initial microstructure; subsequent images are taken from the same place in the joint at 333 thermal cycle increments (except for 2000 cycles); the bottom image represents 2300 thermal cycles. These joints correspond to a nominal shear strain of $23 \%$. The joint width is $0.3 \mathrm{~mm} 0.01$ (inches). XBB899-8139 

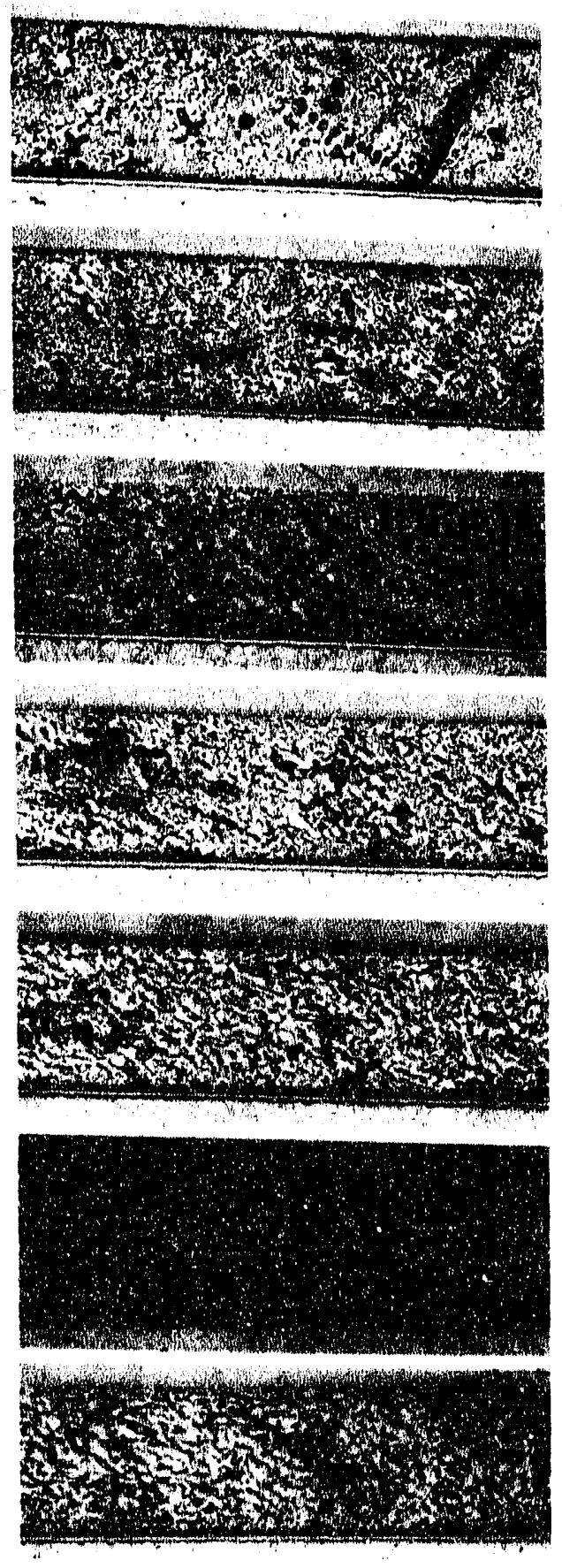

$200 \mu \mathrm{m}$

Figure 28. A series of optical micrographs showing the microstructural evolution of a $58 \mathrm{Sn}-10 \mathrm{~Pb}-2 \mathrm{In}$ solder joint as it is cycled between $-55^{\circ} \mathrm{C}$ and $125^{\circ} \mathrm{C}$. Coarsening of the solder is already apparent with 670 thermal cycles. Coarsening initiates at the coarsened degenerate material at the colony boundaries and slowly consumes the entire solder microstructure. The top image is the initial microstructure; subsequent images are taken from the same place in the joint at 333 thermal cycle increments (except for 2000 cycles); the bottom image represents 2300 thermal cycles. No cracking is visible in this joint after 2300 thermal cycles. These joints correspond to a nominal shear strain of $23 \%$. The joint width is $0.3 \mathrm{~mm}$ ( 0.01 inches). XBB899-8140 


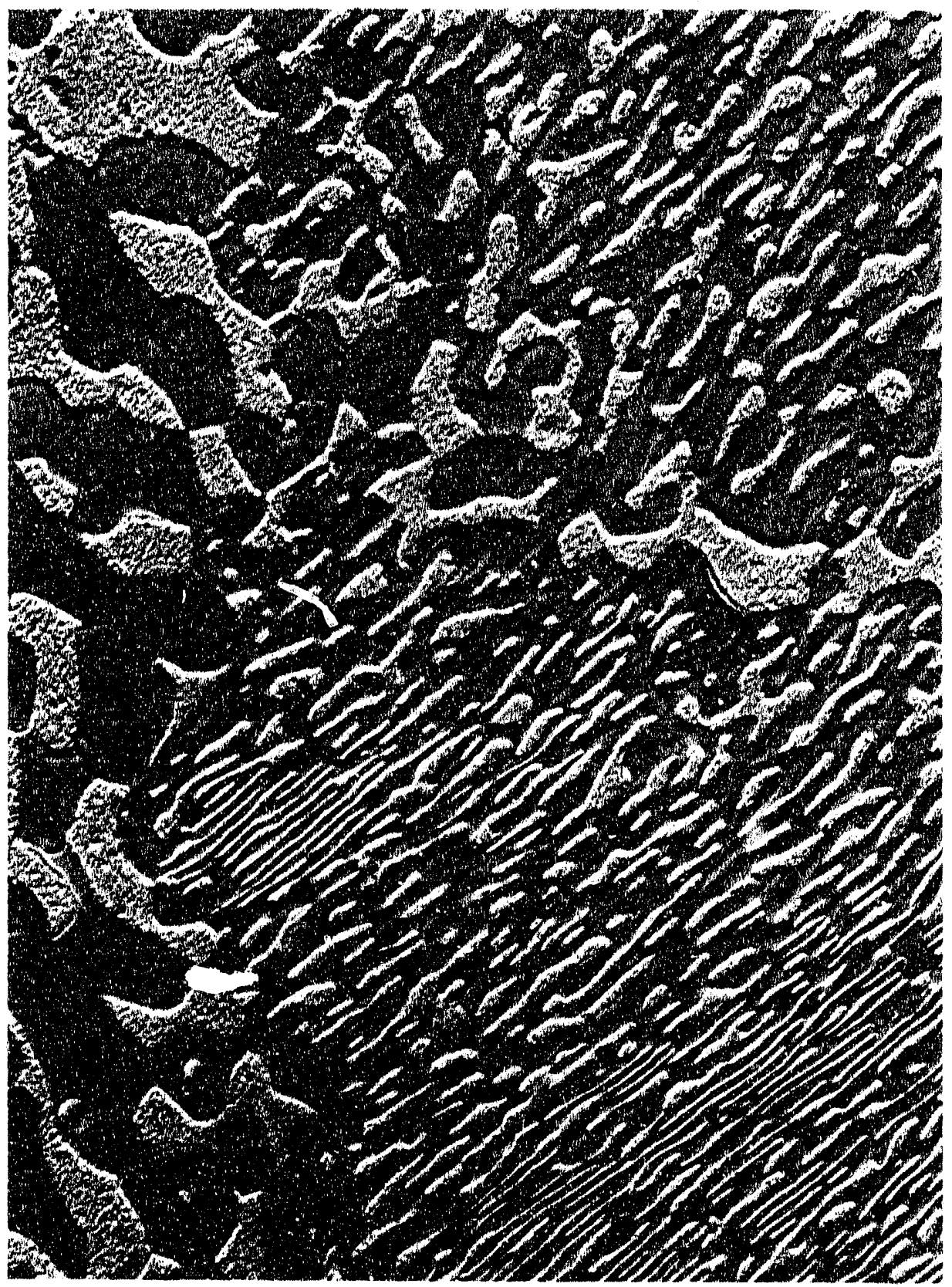

$10 \mu \mathrm{m}$

Figure 29. High magnification SEM micrograph showing the definition and detail of the coarsened band that develops during thermal fatigue of a $60 \mathrm{Sn}-40 \mathrm{~Pb}$ solder joint. Within the coarsened band, individual $\mathrm{Pb}$-rich and $\mathrm{Sn}$-rich phase grains are readily discernible. The light regions are the $\mathrm{Pb}$-rich phase, the dark regions are the $\mathrm{Sn}$-rich phase. XBB882-1436 


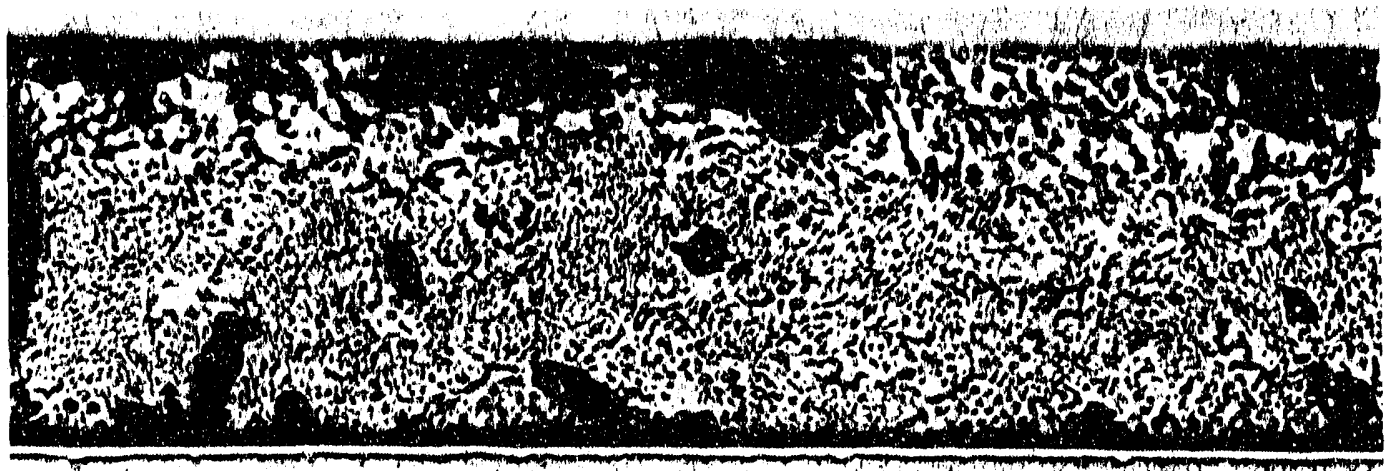

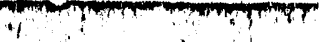
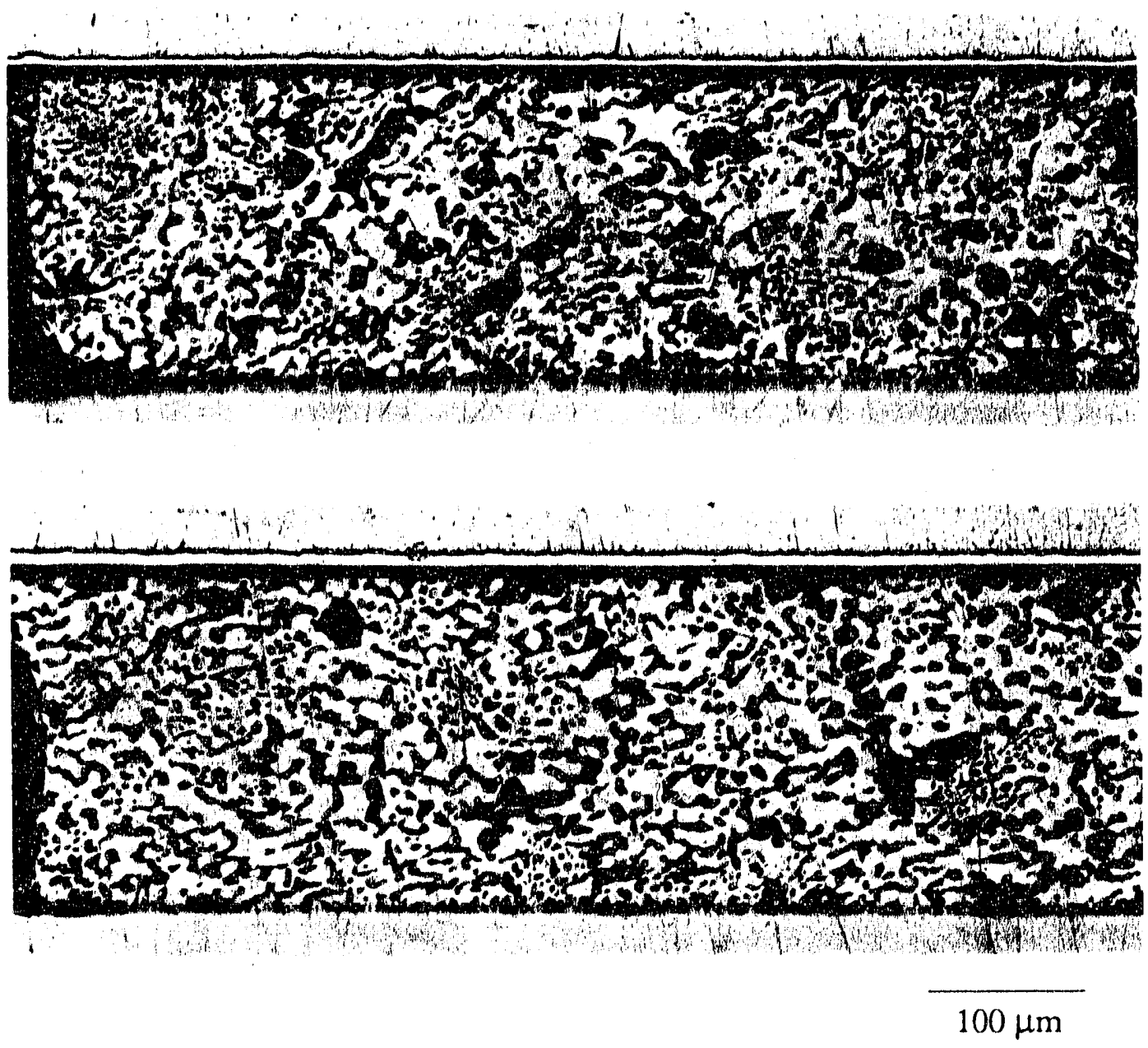

Figure 30. The binary (top), Cd (middle), and In (bottom) solders after 3000 thermal cycles at a nominal shear strain of $15 \%$. Only the binary solder has failed. XBB899-8142 

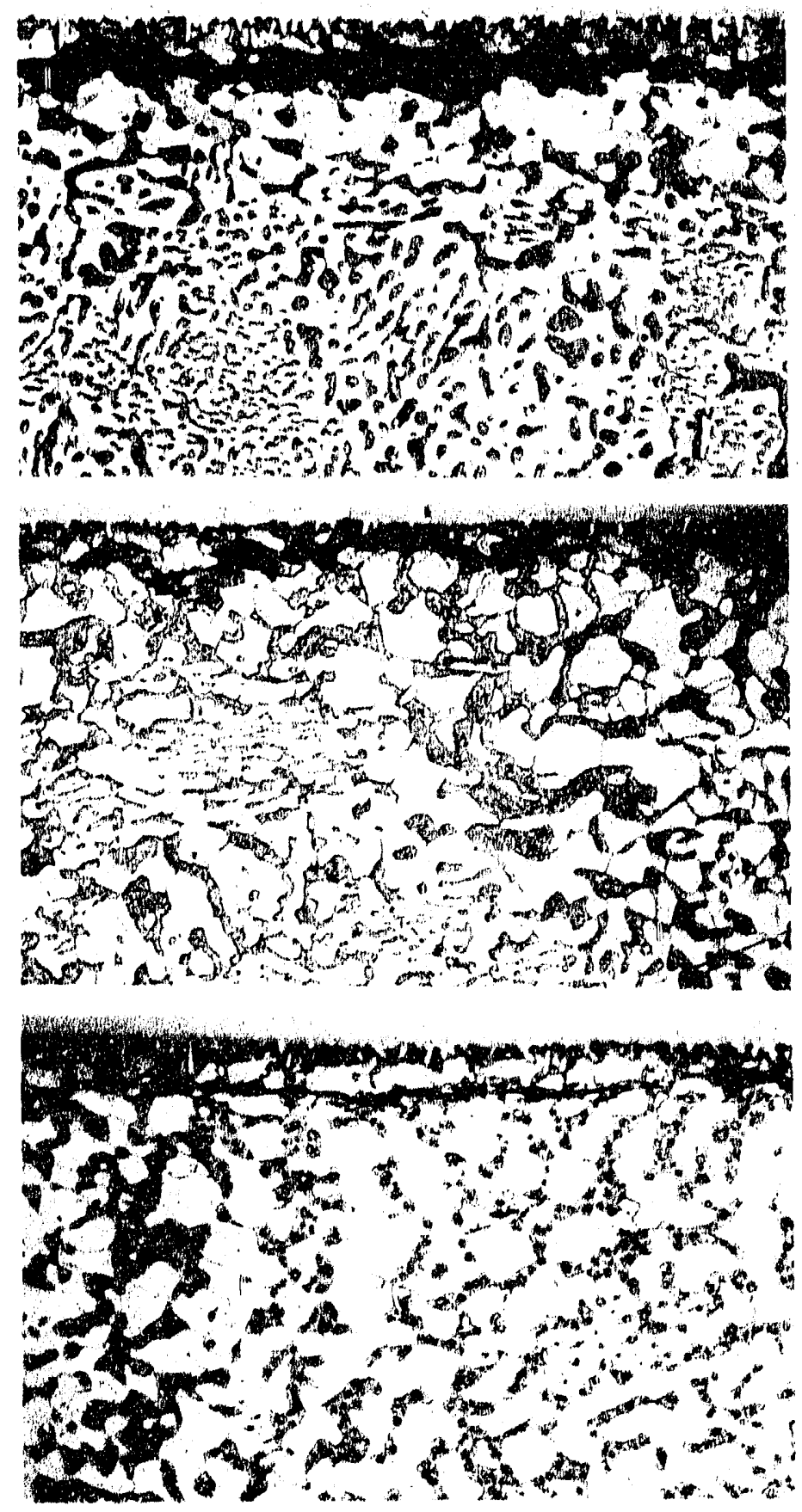

$25 \mu \mathrm{m}$

Figure 31. Optical micrographs showing several thermally fatigued solder joints, 3000 cycles between $-55^{\circ} \mathrm{C}$ and $125^{\circ} \mathrm{C}$ at a nominal shear strain of $23 \%$. (top) A $60 \mathrm{Sn}-40 \mathrm{~Pb}$ joint showing the definition and equiaxed grain structure of the coarsened band material. Joint cracking has occurred exclusively through this coarser microstructure. (middle) $58 \mathrm{Sn}-40 \mathrm{~Pb}-2 \mathrm{In}$ and (bottom) $58 \mathrm{Sn}-40 \mathrm{~Pb}-2 \mathrm{Cd}$ solder joints after the same thermal treatment. Both these solder joints are still intact. These alloyed solder joint microstructures have coarsened with the thermomechanical exposure; however, the coarsening is global and not confined to a band near the solder substrate interface. XBB899-8278 


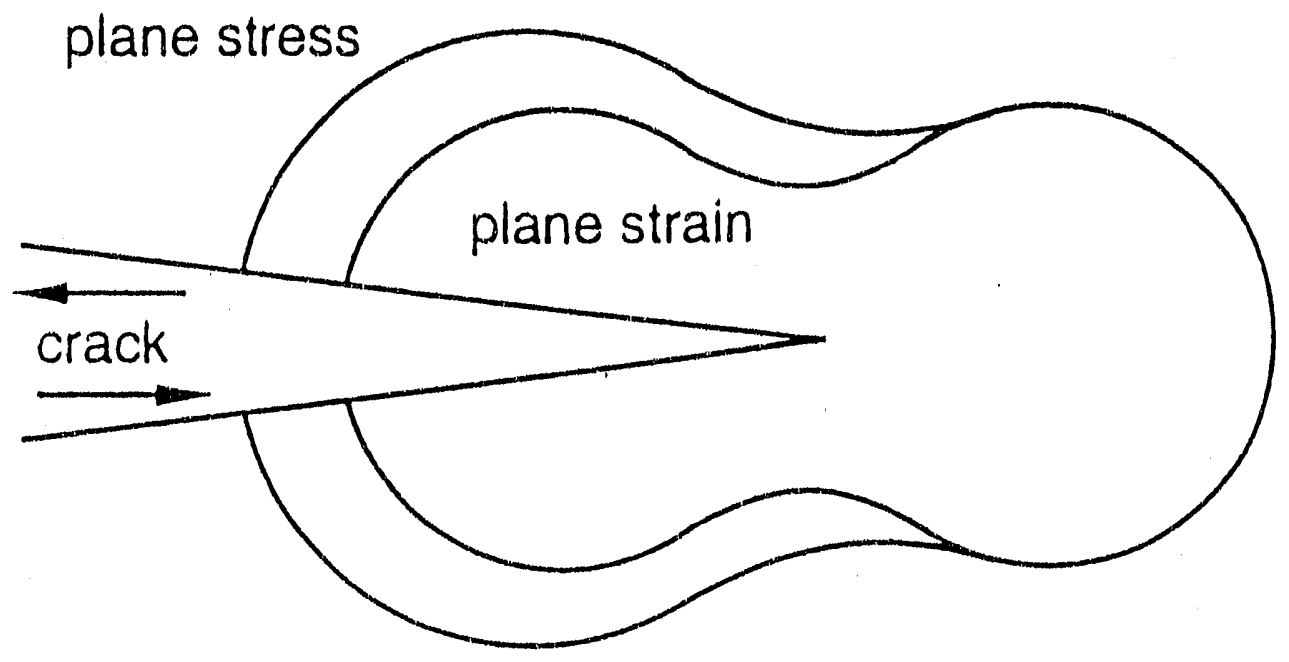

Figure 32. The plastic deformation field ahead of a mode II crack in a Von Mises material (after McKlintock et al.[76]). 


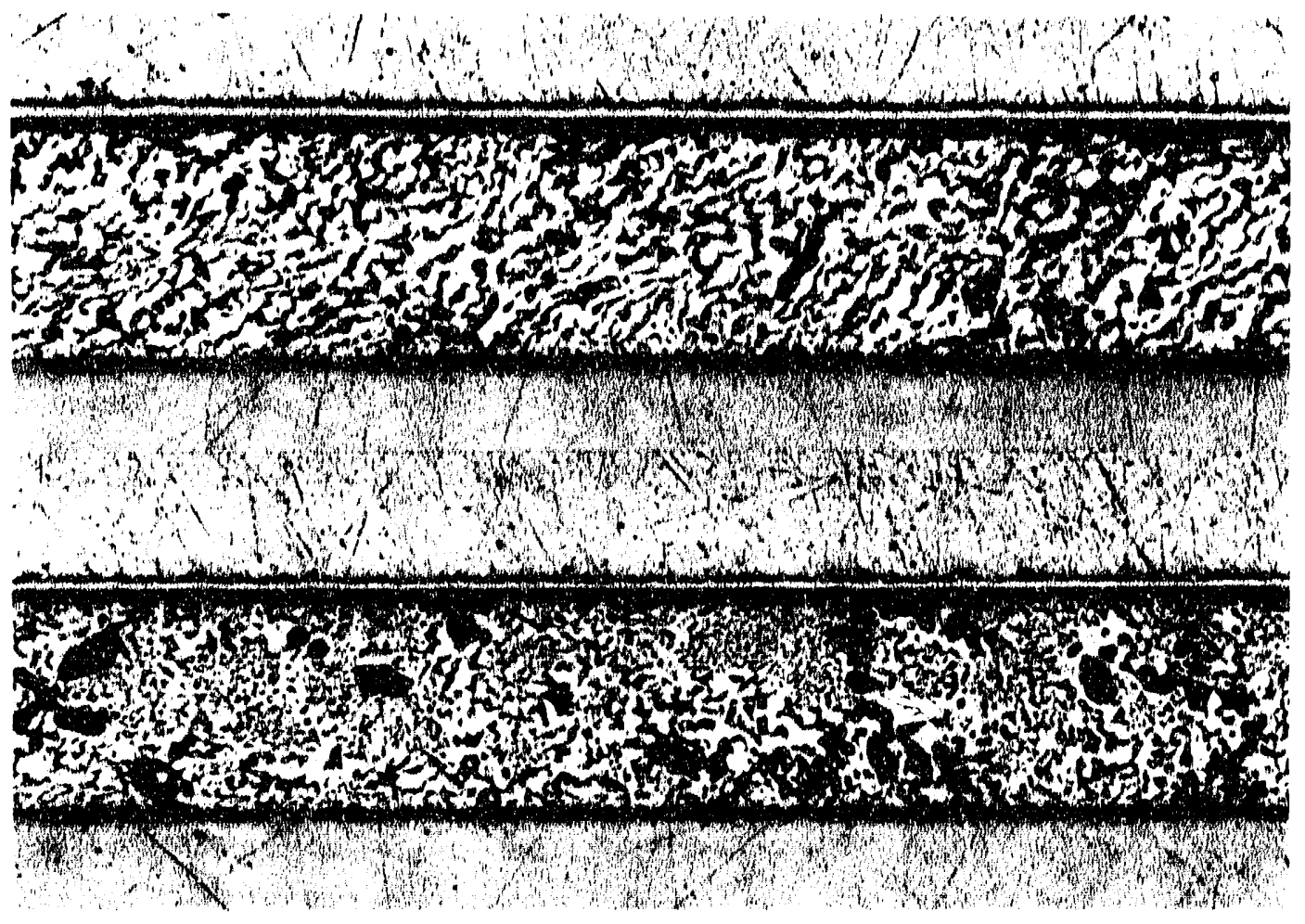

$75 \mu \mathrm{m}$

Figure 33. Optical micrographs of a thermally fatigued In alloyed solder joint. (top) A region in the specimen that experienced a nominal shear strain of $20 \% \mathrm{fo}^{-} 2000$ cycles has coarsened uniformly across the entire joint width. (bottom) A region in $l_{1}$ specimen that experienced only temperature cycling without shear strain, i.e. a region from the center of the specimen illustrated in Figure 12, shows no similar coarsening. The joint width is $0.3 \mathrm{~mm}(0.01$ inches). XBB902-1452 


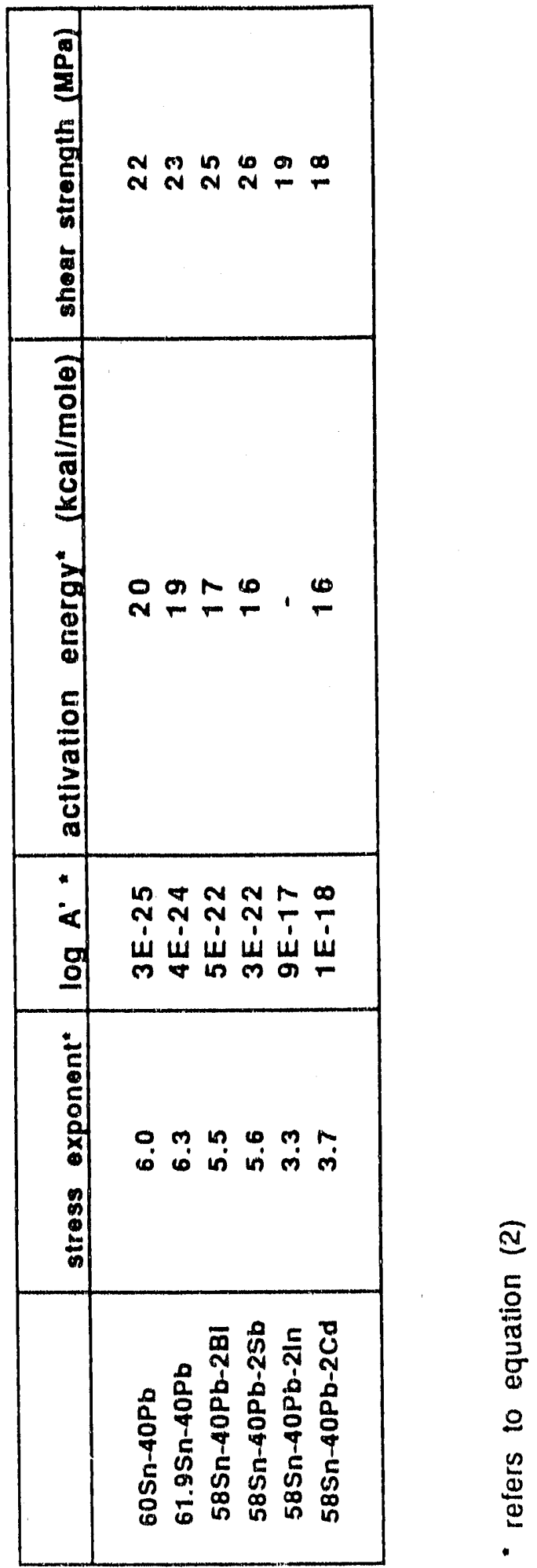

$\frac{0}{2}$

ลิ

응 


\section{ACKNOWLEDGEMEN'T}

Special thanks are extended to Professor J.W. Morris for guidance and critical discussion during the course of my studies. I must also acknowledge P.E. Johnson and E. S. Medearis whose friendship and continued support contributed immeasurably to the completion of this work. This work was supported by the Director, Office of Basic Energy Sciences, U.S. Department of Energy, under contract no.DE-AC03-76SF00098. 

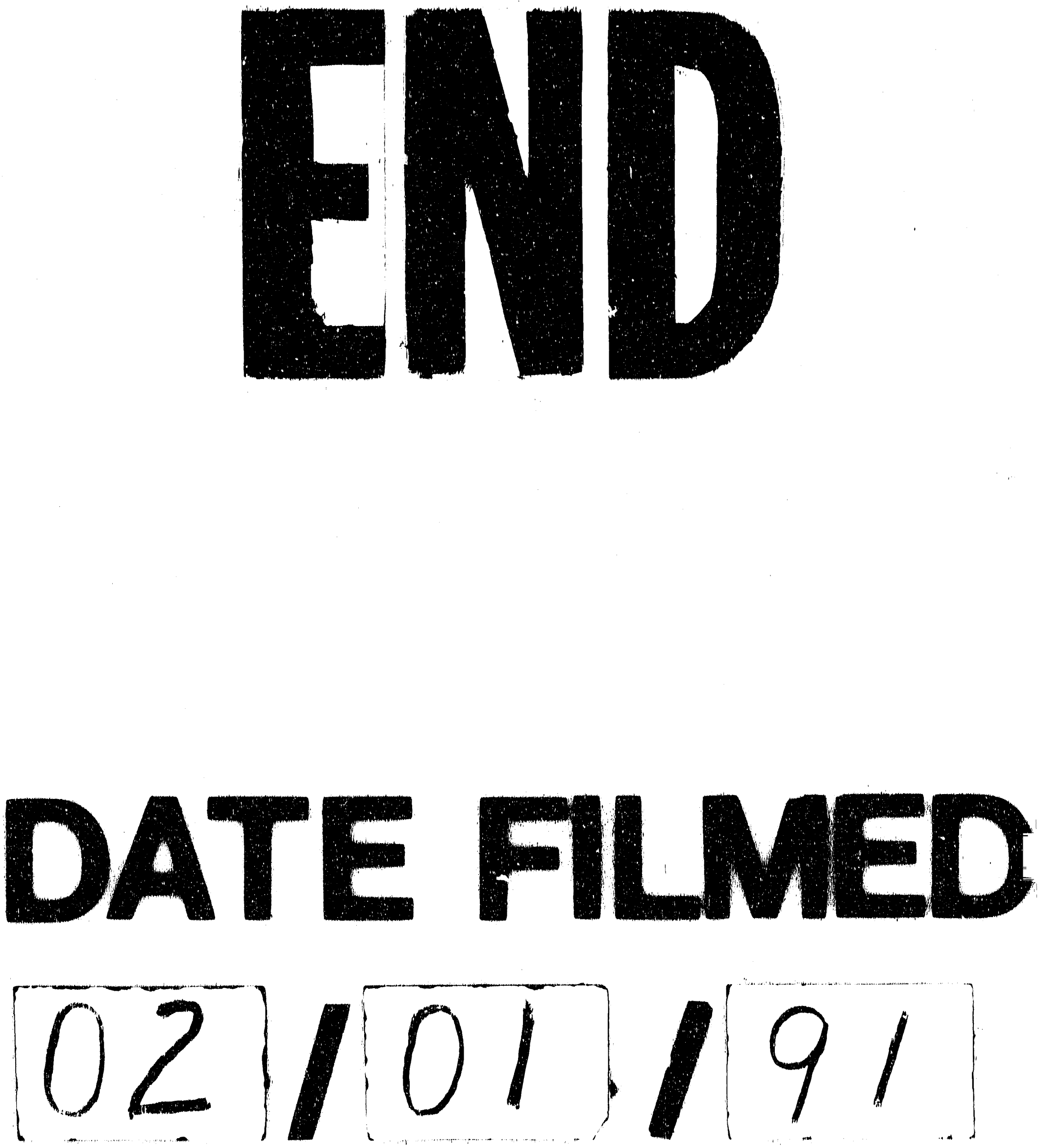
